\title{
Vesicular and Extravesicular Protein Signatures From the Airspaces of Ozone-Exposed Mice Reflect Muco-Inflammatory Disturbances.
}

Ishita Choudhary

Louisiana State University

Thao Vo

Louisiana State University

Kshitiz Paudel

Louisiana State University

Richa Gupta

University of North Carolina at Chapel Hill

Mehmet Kesimer

University of North Carolina at Chapel Hill

Sonika Patial

Louisiana State University

Yogesh Saini ( $\nabla$ ysaini@lsu.edu )

Louisiana State University

\section{Research Article}

Keywords: Ozone, lung, exosomes, proteomics, inflammation, airspaces, homeostasis

Posted Date: December 29th, 2020

DOl: https://doi.org/10.21203/rs.3.rs-132766/v1

License: (9) This work is licensed under a Creative Commons Attribution 4.0 International License.

Read Full License 
1 Title: Vesicular and extravesicular protein signatures from the airspaces of ozone-exposed mice

2 reflect muco-inflammatory disturbances.

3

4 Authors: Ishita Choudhary ${ }^{\mathrm{a}}$, Thao Vo ${ }^{\mathrm{a}}$, Kshitiz Paudel $^{\mathrm{a}}$, Richa Gupta ${ }^{\mathrm{b}}$, Mehmet Kesimer ${ }^{\mathrm{b}}$, Sonika

$5 \quad$ Patial $^{\mathrm{a}}$, Yogesh Saini ${ }^{\mathrm{a}, 1}$

6

7 Author's Affiliations: ${ }^{a}$ Department of Comparative Biomedical Sciences, School of Veterinary

8 Medicine, Louisiana State University, Baton Rouge, LA 70803, USA, bepartment of Pathology

9 and Lab. Medicine, UNC School of Medicine, Chapel Hill, NC 27510, USA

$13{ }^{1}$ Corresponding author:

14 Yogesh Saini, BVSc \& AH, MVSc, PhD

15 Department of Comparative Biomedical Sciences,

16 School of Veterinary Medicine, Louisiana State University,

171909 Skip Bertman Drive,

18 Baton Rouge, LA 70803, USA

19 Phone: $225-578-9143$

20 Fax: 225-578-9895

21 E-mail: ysaini@1su.edu

24 Keywords: Ozone, lung, exosomes, proteomics, inflammation, airspaces, homeostasis

29 Funding: This work was supported by National Institute of Environmental Health Sciences

30 Grant R01ES030125 (to Y.S.). 
33 Abstract: Lung epithelial lining fluid (ELF) harbors a variety of proteins that influence

34 homeostatic and stress responses in the airspaces. Exosomes, nano-sized extracellular vesicles,

35 contain a large number of proteins that vary in abundance and composition based on the

36 prevailing conditions. Ozone causes inflammatory responses in the airspaces of experimental

37 animals and humans. However, in ozone-exposed lung airspaces, the protein signatures in

38 exosomes contained within the ELF remain poorly characterized. To explore this, we

39 hypothesized that ozone triggers the release of inflammatory proteins from various cells that

40 reflect ozone-induced tissue pathology. Accordingly, we sub-chronically exposed adult male and

41 female mice to $0.8 \mathrm{ppm}$ ozone or air and determined exosome-bound proteomic signatures as

42 well as the levels of soluble inflammatory mediators in the bronchoalveolar lavage fluid (BALF).

43 Principal component analyses of the exosome-bound proteome revealed a clear distinction

44 between air-exposed and ozone-exposed mice, as well as between ozone-exposed males and

45 ozone-exposed females. In addition to 575 proteins that were enriched in both sexes upon ozone 46 exposure, 243 and 326 proteins were enriched uniquely in ozone-exposed males and females,

47 respectively. Ingenuity pathway analyses on enriched proteins between ozone- and air-exposed

48 mice revealed enrichment of pro-inflammatory pathways. More specifically, macrophage-

49 activation associated proteins were enriched in exosomes from ozone-exposed mice. Cytokine

50 analyses on the BALF revealed elevated levels of G-CSF, MIP-1 $\beta$, KC, IP-10, IL-6, and IL-5 in

51 ozone-exposed mice. Finally, histopathological assessment revealed significantly enhanced

52 intracellular localization of inflammatory proteins including MUC5B and FIZZ1 in ozone-

53 exposed mice in cell-specific manner indicating the cellular sources of the proteins that are

54 ferried in the exosomes upon ozone-induced lung injury. Collectively, this study identified exosomal, secretory, and cell-specific proteins and biological pathways following sub-chronic exposure of mice to ozone. 


\section{Introduction}

64 Exosomes are nano-sized extracellular vesicles (EV) that originate from the endosomal compartment of the cells and are known to contain biomolecules including proteins, lipids, RNA, DNA, and metabolites ${ }^{1,2,3}$. The composition of these biomolecules in the bodily fluids such as plasma ${ }^{4,5}$, epithelial lining fluid (ELF) ${ }^{6,7}$, saliva ${ }^{8}$, milk ${ }^{8}$ and urine ${ }^{8,9}$ may yield valuable information about their cellular origin, physiological role, presence of pathological stress, and, clinically, may have diagnostic and prognostic values 10,11, 12. All eukaryotic cells release exosomes in healthy as well as stressed conditions and the relative composition of exosomes derived from a variety of cell types lining the body cavity contributes to the overall heterogeneity of the exosome population. Following release into the extracellular milieu, the biological activities of exosomes are mediated either through their direct interaction with the target cells or through their role as a messenger in cell-cell communication ${ }^{13}$. Accordingly, the exosomal cargo proteins can play important roles in the maintenance of tissue homeostasis as well as the propagation of stress responses.

The epithelial lining fluid (ELF), a thin liquid layer covering the epithelial cells in airway and alveolar spaces, contains exosomes that are released from the resident (during homeostasis) and/or recruited cells (in stressed conditions) ${ }^{14}$. Encounters between inhaled entities and the cellular and/or molecular constituents of the ELF of the respiratory tract results in altered composition of the exosome population in the respiratory tract ${ }^{3,15}$. For example, hyperoxia exposure as well as acid inhalation resulted in elevated levels of exosomes in the BALF of mice 16. However, a detailed proteomic analysis on the exosomes of the bronchoalveolar lavage fluid (BALF) origin has never been conducted.

Ozone inhalation causes lung injury and inflammatory responses in experimental animals and humans. Accordingly, we hypothesized that subchronic ozone exposure triggers the release of inflammatory proteins from various cells that reflect the ozone-induced tissue pathology. Previous studies suggested that, as compared to ozone-exposed males, ozone-exposed females exhibit exaggerated inflammatory responses. Accordingly, our second hypothesis was that exosomes from ozone-exposed females possess unique protein signatures that cause exaggerated inflammatory

91 responses. To test these hypotheses, we subchronically exposed adult males and females to filtered

92 air (air) or $0.8 \mathrm{ppm}$ ozone and analyzed the BALF for the presence of exosomal cargo protein 93 signatures as well as for soluble inflammatory mediators. In addition, we also assessed the cell- 
94 specific localization of protein signatures in response to ozone exposure. This study revealed 95 several interesting findings related to ozone- and sex-specific protein signatures within the 96 pulmonary airspaces.

97

98

99

100

101

102

103

104

105

106

107

108

109

110

111

112

113

114

115

116

117

118

119

120

121

122

123

124 
Materials and Methods:

126 Animal husbandry: Male and female mice on C57BL/6 background were procured from Jackson 127 Laboratory (Bar Harbor, ME). Upon arrival at Louisiana State University (LSU) vivarium, mice 128 were allowed to acclimatize for three weeks. Mice were maintained in individually ventilated, hot129 washed cages on a 12-hour dark/light cycle. Except during the exposures schedule, mice were maintained on regular diet and water ad libitum. All the procedures were performed after approval

131 by the LSU Institutional Animal Care and Use Committee (IACUC) and authors complied with 132 the Animal Research: Reporting of In Vivo Experiments (ARRIVE) guidelines.

134 Experimental design and ozone exposure: Male and female mice, housed in separate cages, were 135 exposed to HEPA-filtered air (air) or ozone $(806.1 \pm 2.68 \mathrm{ppb} ; 4 \mathrm{~h}$ per day) for 14 days (five consecutive days of exposure, two days of rest, five consecutive days of exposure, two days of rest,

137 four consecutive days of exposure). Tissues were harvested from experimental mice 12-16 hours 138 after the end of the last exposure. Of note, BALF samples and lung tissues were harvested from 139 the same cohort of mice that were exposed to air or ozone for our recently published study ${ }^{17}$.

$140 \quad$ Hatch et al. reported that 4-5 times higher ozone concentration is required in rodents to 141 exhibit lung inflammatory responses comparable to those of exercising humans ${ }^{18,19,20}{ }^{\text {. The ozone }}$ 142 concentration used in this study was $\sim 11.5$ fold higher than $0.07 \mathrm{ppm}$, an 8 hours National Ambient 143 Air Quality Standards (NAAQS) for ozone.

144 Previous reports have highlighted sex-associated differences in the susceptibility to ozone145 induced lung injury and inflammation 21,22,23,24; therefore, both sexes were exposed to air or ozone.

146 To replicate real-life exposure conditions of humans during the active phase, mice were exposed 147 in the nightly conditions, a state of higher physically activity in mice ${ }^{25}$. Briefly, the loading of 148 animals onto the light-tight chambers was coordinated with the start of the night cycle at the 149 vivarium. All the exposures took place between 6:00PM-11:00PM.

Necropsy and tissue harvesting: Mice were anesthetized with an intraperitoneal injection of 152 2,2,2-tribromoethanol (250mg/kg; Sigma-Aldrich, St Louis, MO) and thoracotomy was performed 153 to expose lungs and extrapulmonary airways. A 20-gauge cannula was inserted into the trachea 154 and secured in place with a suture. Lungs were lavaged with a calculated volume (Body weight in 155 grams x $0.035 \times 1000=$ volume in $\mu$ l) of ice-cold Dulbecco's phosphate-buffered saline (DPBS) 
156 without calcium and magnesium. The first two lavages were pooled and stored on ice. To increase 157 the exosome yield, further lavages were performed to collect additional $9 \mathrm{ml}$ of BALF. Three 158 hundred microliters from the first two lavages was centrifuged at $500 \mathrm{~g}$ for 5 minutes at $4^{\circ} \mathrm{C}$ in 159 order to pellet the cells. Cell-free supernatant was saved at $-80^{\circ} \mathrm{C}$ for cytokine analyses. The 160 remaining portion of the first two lavages and $9 \mathrm{ml}$ volume of serial lavages were pooled and 161 centrifuged (as above) to remove the cells. To increase the exosome yield, cell-free BALF from 162 three individual mice with similar treatment and sex were pooled.

164 Exosome isolation from bronchioalveolar lavage fluid (BALF): Exosomes were isolated by a 165 differential ultracentrifugation method as previously described with some modifications ${ }^{26}$. Briefly, 166 the BALF from three gender- and treatment-matched mice were pooled and centrifuged at 500g 167 for 5 min to sediment the BALF immune cells. The cell-free supernatant was further centrifuged 168 at $3000 \mathrm{~g}$ for $10 \mathrm{~min}$ to sediment the dead cells. Then, the supernatant was centrifuged at $10,000 \mathrm{~g}$ 169 for 70 min using SW28 rotor (Beckman Coulter Optima L-90 K Ultracentrifuge). The pellet comprising of cell debris and large microvesicles was discarded and the supernatant was filtered using a $0.2 \mu \mathrm{m}$ filter (VWR, Radnor, PA). The filtered supernatant was further centrifuged at $172100,000 \mathrm{~g}$ for $100 \mathrm{~min}$. The supernatant was carefully discarded without disturbing the pellet. The 173 pellet was resuspended in $200 \mu \mathrm{l}$ of phosphate buffered saline (PBS). Nanoparticle tracking 174 analyses (NTA; Nanosight 300) on vesicular population harvested using differential 175 ultracentrifugation method typically have a mean diameter of $131.2 \pm 4.4 \mathrm{~nm}$ (mean \pm SEM) and $176102.4 \pm 5.8 \mathrm{~nm}$ (mode $\pm \mathrm{SEM}$ ). Resuspended exosomes were snap-frozen and stored at $-80^{\circ} \mathrm{C}$. All 177 the centrifugation steps were performed at $4^{\circ} \mathrm{C}$.

179 Sample preparation for proteomic analyses: Proteins were reduced, alkylated, and purified by 180 chloroform/methanol extraction prior to digestion with sequencing grade modified porcine trypsin 181 (Promega, Madison, WI). Tryptic peptides were then separated by reverse-phase XSelect CSH $182 \mathrm{C} 182.5 \mu \mathrm{m}$ resin (Waters) on an in-line $150 \times 0.075 \mathrm{~mm}$ column using an UltiMate 3000 183 RSLCnano system (Thermo). Peptides were eluted using a 90 min gradient from 97:3 to 60:40 184 buffer $\mathrm{A}: \mathrm{B}$ ratio (Buffer $\mathrm{A}=0.1 \%$ formic acid, $0.5 \%$ acetonitrile; Buffer $\mathrm{B}=0.1 \%$ formic acid, $18599.9 \%$ acetonitrile). Eluted peptides were ionized by electrospray $(2.15 \mathrm{kV})$ followed by mass 186 spectrometric (MS) analysis on an Orbitrap Eclipse Tribrid mass spectrometer (Thermo Fisher 
187 Scientific, Waltham, MA). MS data were acquired using the FTMS analyzer in profile mode at a 188 resolution of 120,000 over a range of 375 to $1200 \mathrm{~m} / \mathrm{z}$. Following HCD activation, MS/MS data 189 were acquired using the ion trap analyzer in centroid mode and normal mass range with a 190 normalized collision energy of $30 \%$.

191 Data analysis - intensities: Proteins were identified by database search against the UniprotKB 192 database restricted to Mus musculus (November 2019) using MaxQuant (version 1.6.10.43, Max 193 Planck Institute) with a parent ion tolerance of $3 \mathrm{ppm}$ and a fragment ion tolerance of $0.5 \mathrm{Da}$. 194 Protein identifications were accepted if they could be established with less than $1.0 \%$ false 195 discovery and contained at least 2 identified peptides. Protein probabilities were assigned by the 196 Protein Prophet algorithm ${ }^{27}$. Proteins were normalized to iBAQ MS1 intensities within MaxQuant 197 and quality was assessed using the UAMS Bioinformatics core in-house ProteiNorm tool, a user198 friendly tool for a systematic evaluation of normalization methods, imputation of missing values 199 and comparisons of different differential abundance methods. Popular normalization methods are 200 evaluated including $\log 2$ normalization (Log2), median normalization (Median), mean 201 normalization (Mean), variance stabilizing normalization (VSN) ${ }^{28}$, quantile normalization

202 (Quantile) ${ }^{29}$, cyclic loess normalization (Cyclic Loess) ${ }^{30}$, global robust linear regression 203 normalization (RLR) ${ }^{31}$, and global intensity normalization (Global Intensity) ${ }^{31}$. The individual 204 performance of each method can be evaluated by comparing the following metrices: total intensity, 205 Pooled intragroup Coefficient of Variation (PCV), Pooled intragroup Median Absolute Deviation 206 (PMAD), Pooled intragroup estimate of variance (PEV), intragroup correlation, sample correlation 207 heatmap (Pearson), and log2-ratio distributions. The data were normalized using VSN as this 208 method had the lowest intragroup variance and highest intragroup correlation. The Log2 VSN 209 normalized iBAQ MS1 intensities were used to perform statistical analysis using Linear Models 210 for Microarray Data (limma) with empirical Bayes (eBayes) smoothing to the standard errors ${ }^{30}$. 211 Proteins with an adjusted p-value $<0.05$ and a fold change (FC) $>2$ were considered to be 212 significant. Significant proteins were used to identify important protein networks and pathways 213 using the Ensemble of Gene Set Enrichment Analyses (EGSEA) Bioconductor package ${ }^{32}$.

214 Ingenuity pathway and protein interaction networks analyses: The Ingenuity pathway analysis 215 (IPA) identifies canonical pathways and biological networks that are activated in the queried data 216 set. The differentially expressed proteins in ozone-exposed mice were subjected to IPA to 
217 investigate the biological networks and pathways that were enriched in the exosomes (Qiagen,

218 Redwood City, CA). Core analysis function was selected to screen proteins that met our cutoff 219 criteria $(\mathrm{FC}>2, \mathrm{FDR}<0.05)$. STRING analysis was performed to identify protein-protein 220 interaction network enrichment in enriched proteins ${ }^{33}$. The STRING (https://string-db.org; 221 version 11.0) maintains a database of known and predicted protein-protein interaction (PPI) 222 networks.

223 Analyses of BALF for Cytokines: Cell-free BALF was assessed for granulocyte-colony 224 stimulating factor (G-CSF), macrophage inflammatory protein 1-beta (MIP-1ß/CCL4), 225 keratinocyte chemoattractant (KC/CXCL1), IP-10, IL-6, and IL-5, using a Luminex XMAP-based 226 assay (MCYTOMAG-70K), according to manufacturer's instructions (EMD Millipore, Billerica, 227 MA).

Immunohistochemical analyses: A separate cohort of mice was exposed to air or ozone to 230 harvest unlavaged lung lobes for histopathological tissue preparation. Lungs were inflated with a 231 calculated volume (Bodyweight in grams x $0.035 \times 1000=$ volume in $\mu 1$ ) of $10 \%$ neutral buffered 232 formalin. Formalin-fixed trachea and transverse sections of lung lobes were paraffin embedded 233 and $5 \mu \mathrm{m}$ thick sections were mounted onto glass slides. Sections were processed for 234 immunohistochemical staining.

Immunohistochemistry for MUC5B and RETNLA (FIZZ1/RELM $\alpha$ ): Formalin-fixed 237 paraffin-embedded lung sections were processed to assess immunohistochemical localization of 238 MUC5B, as previously described ${ }^{34,35}$. Rabbit monoclonal RETNLA (FIZZ1) primary antibody 239 (ab39626; ABCAM Cambridge, MA) was used to probe lung sections.

241 Statistical analyses: One-way Analysis of Variance (ANOVA) followed by Tukey's post hoc test 242 for multiple comparisons was used to determine significant differences among groups. All data 243 were expressed as mean \pm standard error of the mean (SEM). Statistical analyses were performed 244 using GraphPad Prism 8.0 (GraphPad Software, La Jolla, CA). A p-value of less than 0.05 was 245 considered statistically significant. 
Results:

248 Ozone exposure results in exaggerated lung injury and a robust increase in BALF cytokine 249 levels

To assess lung injury in response to ozone, we analyzed the total protein contents of cellfree BALF, an indicator of alveolar-endothelial gas exchange barrier damage ${ }^{36,37}$. While the BALF protein contents in air-exposed mice were comparable between males $(122.5 \pm 8.9 \mu \mathrm{g} / \mathrm{ml})$ and females $(124.3 \pm 7.1 \mu \mathrm{g} / \mathrm{ml})$, both ozone-exposed males $(568.8 \pm 42.5 \mu \mathrm{g} / \mathrm{ml})$ and females $(1012.0 \pm 159.9 \mu \mathrm{g} / \mathrm{ml})$ had significantly elevated protein contents (Fig. 1A). Further, BALF protein contents in ozone-exposed females were significantly higher than those in ozone-exposed males (Fig. 1A).

To determine the levels of soluble inflammatory mediators in the airspaces, we assessed levels of 25 cytokines in the BALF from air- and ozone-exposed mice. Only six of the analyzed cytokines showed significant differences between air- and ozone-exposed mice. While air-exposed males and females had basal or undetectable levels of all these six cytokines, ozone exposure resulted in significant elevation in the concentration of these six cytokines, i.e., G-CSF, MIP-1 $\beta$, KC, IP-10, IL-6, and IL-5, in either one or both the sexes (Fig. 1B-G). Although ozone-exposed males had elevated levels of all the six cytokines, only three of them, i.e., KC, IP-10, and IL-6, were found to be significantly elevated (Fig. 1D-F). Ozone-exposed females, however, had significantly elevated levels of all the six cytokines. Two of the analyzed cytokines, i.e., G-CSF

(Fig. 1B) and MIP-1 $\beta$ (Fig. 1C), were significantly elevated in ozone-exposed females versus ozone-exposed males.

Next, we assessed the concentration of double-stranded DNA (dsDNA), an indicator of airway neutrophilic inflammation ${ }^{38,39}$. BALF dsDNA levels were comparable between airexposed males and air-exposed females (Fig. 1H). BALF from both ozone-exposed males and ozone-exposed females had significantly elevated levels of dsDNA, as compared to the respective

272 control groups. The dsDNA levels were significantly higher in ozone-exposed females versus 273 ozone-exposed males (Fig. 1H).

\section{Isolation and assessment for exosome-specific markers}

Cell-free BALF was subjected to differential centrifugation to sediment exosomes (Fig. 2A). Total protein contents in the exosomes from air-exposed males $(41.2 \pm 1.6 \mu \mathrm{g})$ were 
278 comparable with air-exposed females $(39.7 \pm 0.7 \mu \mathrm{g})$. While the total protein contents in the

279 exosomes from ozone-exposed mice were $\sim 2$ fold higher as compared to air-exposed mice, protein 280 contents were comparable between ozone-exposed male $(91.7 \pm 3.6 \mu \mathrm{g})$ and exposed female $(87.2$ $281 \pm 4.4 \mu \mathrm{g})$ mice (Fig. 2B).

282 Next, a list of 1225 exosomal protein signatures was retrieved from the Exocarta 283 Vesiclepedia database. This list contained proteins that fulfilled designated criteria (Species-Mus 284 Musculus; Tissues/cell type-Lung cells, macrophages, mast cells, fibroblast, BALF, B cells, 285 Plasma, Serum and thymus; Cell line-dendritic cells, macrophages, mast cells, myeloid-derived 286 suppressor cells, and T-cells; Isolation methods-all reported; Detection methods-ELISA, Mass 287 spectrophotometry, immunoelectron microscopy, and western blotting; Vesicle types-Exosomes). 288 Out of 1225 exosomal protein signatures, 822 were identified in BALF exosomes collected in this 289 study (Fig. 2C). Next, through manual literature search, we generated a list of proteins that are 290 known as exosome-specific signature proteins. While all of these 50 known exosome markers were 291 present in all the 12 exosome samples, at least 29 of these proteins were represented in the top 20\% 292 of the most abundant proteins (Fig. 2D).

\section{Exosomes from filtered air-exposed mice contain lung cell-specific proteins}

A total of 3258 proteins were identified in exosomes from air-exposed mice. While 2361 proteins were present in all six ( 3 males; 3 females) exosome samples from air-exposed mice, 320 ,

$297185,137,129$, and 126 additional proteins were identified in at least 5, 4, 3, 2, and 1 exosome 298 samples from air-exposed mice, respectively. A list of 50 most-abundant proteins in exosomes 299 from air-exposed mice is included in Table 1. Our analyses revealed that exosomes from air300 exposed mice contain protein signatures known to be expressed in the lungs including club cell301 specific protein (SCGB1A1; uteroglobin; CCSP), surfactant-associated protein D (SFTPD), 302 surfactant-associated protein B (SFTPB), surfactant-associated protein A1 (SFTPA1), chitinase303 like protein 3 (CHIL3), chitinase-3-like protein 1 (CHI3L1), alpha-1-antitrypsin 1-2 304 (SERPINA1B), serotransferrin (TF), superoxide dismutase (SOD1), and platelet glycoprotein 4 305 (CD36). The presence of these proteins suggests that; 1) the exosome populations are 306 representative of the homeostatic airspaces and, 2) the proteins detected within the exosomes may 307 have potential roles in immune defense and antioxidant responses.

308 Principal component (PC) analyses revealed clear clustering of air-exposed male samples, 
but the air-exposed female samples were somewhat dispersed (Fig. 3A). Next, employing 310 stringent cutoff criteria ( $\log 2$ Fold change $>1$, FDR $<0.05$ ), we compared differentially enriched 311 protein signatures in air-exposed females versus air-exposed males (Table 2A and Fig. 3B). Our 312 analyses identified only 15 differentially enriched (5 upregulated and 10 downregulated) proteins 313 (Table 2A and Fig. 3B).

\section{Exosomes from ozone-exposed mice contain unique protein signatures relevant to lung} inflammation

A total of 3421 proteins were identified in exosomes from ozone-exposed mice. A total of 2756 proteins were present in all six exosome samples from ozone-exposed mice. 288, 139, 108 75 , and 55 proteins were identified in at least $5,4,3,2$, and 1 exosome samples from ozoneexposed mice, respectively. A list of 50 most-abundant proteins in exosomes from ozone-exposed mice is included in Table 1. Comparison of lists indicating 50 most-abundant proteins in exosomes from air-exposed and ozone-exposed mice identified 33 common signatures and 17 treatmentspecific signatures. Seventeen most abundant proteins from the top 50 in exosomes that were specific to ozone treatment included RETNLA, AQP5, HSPA, S100A6, S100A11, HIST1H4A, HIST1H1C, HIST1H2A's, HIST1H2B's, HIST1H3B, and APOA1, a majority of which are known lung inflammation proteins.

PC analyses revealed a clear separation of ozone-exposed female and ozone-exposed male samples. The separation was contributed by PC2 that accounts for $\sim 11 \%$ variance (Fig. 3A). Next, we compared differentially enriched protein signatures in ozone-exposed females as compared to ozone-exposed males (Table 2B and Fig. 3C). Our analyses identified an enrichment of 5 proteins and reduced abundance of 6 proteins (Table 2B and Fig. 3C).

Of note, we found additional differentially enriched proteins that were eliminated from the analyses because those proteins were not detected in one of the groups being compared and were assigned NA designation during the normalization process. 22 such proteins were exclusively present in air-exposed females (Supplemental Table 1A) and 56 such proteins were exclusively present in air-exposed males (Supplemental Table 1B). Further, 23 proteins were exclusively present in ozone-exposed females (Supplemental Table 2A) and 53 proteins were exclusively present in ozone-exposed males (Supplemental Table 2B). Finally, 27 and 168 proteins were exclusively present in the air- and ozone-exposed mice, respectively (Supplemental Table 3). 
Exosomes from ozone-exposed mice are enriched in stress-response proteins in sex-specific manner

The top two principal components ( $\mathrm{PC} 1$ and $\mathrm{PC} 2$ ), that contribute to $\sim 48 \%$ variance, revealed that treatment and sex were the primary drivers of variation in overall protein contents. The PC1, which accounts for $37.19 \%$ of the variance, separated air-exposed mice from ozoneexposed mice. PC2, that accounts for $10.69 \%$ of overall variance, distinctly separated ozoneexposed males and ozone-exposed females (Fig. 3A). Next, a comparison of ozone-exposed males and air-exposed males identified 818 differentially expressed (380, enriched; 438, low-abundance) proteins (Fig. 3D and Supplemental Table 4). Similarly, a comparison of ozone-exposed females and air-exposed females identified 901 differentially expressed (427, enriched; 474, lowabundance) proteins (Fig. 3E and Supplemental Table 4). Using cutoff criteria ( $\log 2 \mathrm{FC}>1$, FDR $<0.05$ ), comparison of ozone-exposed mice (mixed gender) with air-exposed mice (mixed gender) identified 1255 differentially expressed (568, enriched; 687, low-abundance) proteins (Fig.

\section{F and Supplemental Table 4).}

Next, a comparison of proteins that were differentially enriched in ozone-exposed males and ozone-exposed females as compared to sex-matched air-exposed mice identified shared and sex-specific signatures. A total of 575 proteins (263, enriched; 312, low-abundance) were found differentially expressed in both ozone-exposed males and ozone-exposed females as compared to respective sex-matched air-exposed mice (Fig. 3G-H). As compared to exosomes from airexposed males, exosomes from ozone-exposed males contained an additional 243 (117, enriched; 126, low-abundance) uniquely expressed proteins. As compared to exosomes from air-exposed females, exosomes from ozone-exposed females contained 326 (164, enriched; 162, lowabundance) uniquely expressed proteins (FIG. 3G-H).

A list of top shared and sex-specific proteins, relevant to the stress responses, that were found upregulated in ozone-exposed mice is included in Table 3 (Top 50) and Supplemental Table 4 (complete list). Shared protein signatures that were found upregulated in both ozoneexposed males and ozone-exposed females included EPHA2, SLC23A2, SLC26A4, MUC5AC, FN1, POSTN, RETNLA, and various histones (Histone 1, 2, 3). Interestingly, ozone-exposed male mice had significantly upregulated proteins including ITGB6, HSPA2, PTGS2, endophilin-B1 (SH3GLB1) and KEAP1. On the other hand, ozone-exposed female mice had significantly 
upregulated proteins including PTPN3, APOD, MMP3/MMP10, TSPO, PLA2G7, SH3GL1, and 372 PKP3 (Table 3; Top 50).

A summary of the top 50 proteins that had reduced abundance in ozone-exposed mice are included in Table 4 (Top 50) and Supplemental Table 4 (complete list). Proteins that were found downregulated in both ozone-exposed males and ozone-exposed females included MLF1, LSP1, MERTK, FGFR2, CHID1, THBS3, LYZ2, and FGFR2. Interestingly, ozone-exposed male mice had significantly downregulated proteins including FABP1, AFP, VAMP5, and SGSH. Similarly, ozone-exposed female mice had significantly downregulated proteins including TLR5, PRSS1, LMF1, SLC27A1, and MIA3 (Table 4; Top 50)

\section{Macrophage activation-associated proteins are differentially enriched in exosomes from} ozone-exposed mice

Macrophages within the airspaces have been reported to be activated following ozoneexposure $40,41,42$. Next, through manual literature search, we prepared a list of proteins that determine the activation status of the macrophages and categorized them into one of the two activation categories, i.e., classically activated macrophages (CAM, M1) and alternatively activated macrophages (AAM, M2). Significantly upregulated proteins in exosomes from ozoneexposed mice included LGALS3, TGM2, FN1, LMNA, RETNLA, MRC2, ASS1, and PLA2G7 (Fig. 4A). Significantly downregulated proteins in exosomes from ozone-exposed mice included MRC1, CHI3L1, CHIA, CHI3L3 (YM1), PTGS1, and MERTK. Interestingly, MARCKS, CD200, CD36, LCN2, CHI3L4 (YM2) were found elevated only in the females, regardless of their exposure to ozone.

Next, we hypothesized that the macrophage activation protein signatures in the exosomes reflect macrophage activation status following ozone-exposure. Our data did not clearly categorize macrophage activation markers into M1 or M2 categories. While overall, a relatively larger number of M2-associated proteins were upregulated in the exosomes from ozone-exposed mice, the protein signatures largely reflected a mixed phenotype. For example, while some M2associated proteins including RETNLA, TGM2, FN1, MRC2, ASS1, LCN2, LGALS3 were enriched upon ozone exposures, other M2-associated proteins either remained unchanged 400 (CLEC7A, FCERG1 STAT6) or were present in low abundance (ALOX15, CHIA, CHIL3, 
specifically upregulated in the females regardless of their exposure status. While some M1associated markers were enriched (PLA2G7, FCGR2, and LMNA) in the exosomes following ozone exposure, others, such as MARCKS and PTGS2 remained unchanged (Fig. 4A).

RETNLA, commonly known as FIZZ1 (Found in Inflammatory Zone 1), is a well-known marker for alternative macrophage activation, particularly in mice. To determine the cellular source of this protein in the exosomes of ozone-exposed airspaces, we performed immunohistochemical staining on lungs from the air- and ozone-exposed mice (Fig. 4B-G). The majority of the RETNLA-stained cells in air-exposed mice were club cells, however, the staining intensity was very low (Fig. 4B). In contrast, club cells were intensely stained in the ozone-exposed mice (Fig. 4C). In addition to the contrasting staining intensities, an indicator of the differential expression levels of intracellular proteins, the number of RETNLA-stained cells was significantly greater in the ozone-exposed male and female mice (Fig. 4D). Next, we compared RETNLA staining in alveolar macrophages between air- and ozone-exposed mice. The alveolar macrophages did not show any RETNLA staining in air-exposed mice (Fig. 4E). Interestingly, the RETNLA staining in alveolar macrophages from ozone-exposed mice was location-dependent, i.e., intense staining in alveoli adjacent to the terminal bronchioles (Fig. 4F) and no staining in alveoli distal to the terminal bronchioles (Fig. 4G).

Mucoinflammatory disease response proteins were differentially enriched in exosomes from ozone-exposed mice

Elevated levels of ozone contribute to the exacerbation of pulmonary symptoms in patients with mucoinflammatory lung diseases including asthma ${ }^{43,44,45}$ and chronic obstructive pulmonary disease 46,47 . Accordingly, through a manual literature search, we customized a list of proteins that have been reported to be associated with mucoinflammatory lung diseases and assessed their levels in the exosomes from the air- and ozone-exposed mice. Ozone exposure resulted in the enrichment of known mucoinflammatory proteins including LGALS3, FN1, POSTN, S100A9, MUC5AC, MUC5B, APOA1, APOA2, FGA, FGB, and FGG (Fig. 5A). Simultaneously, other known mucoinflammatory proteins showed low abundance in exosomes from ozone-exposed mice versus air-exposed mice. These proteins include MRC1, PLG, ADIPOQ, CHIA, LYZ2, CSF1R, SERPIND1, SFTPB, CHI3L1, SFTPA1, LRG1, and HMGB1 (Fig. 5A).

MUC5B is overproduced in the airspaces of patients with mucoinflammatory lung 
433 diseases including $\mathrm{COPD}^{48}$. To determine the effect of ozone exposure on the intracellular levels 434 of MUC5B in the large versus small airways, we immunohistochemically stained the lung sections 435 and quantified the proportion of cells expressing MUC5B in ozone-exposed versus air-exposed 436 mice (Fig. 5B-G). First-and second-generation airways from air-exposed males and females 437 contained $\sim 16 \%$ and $\sim 35 \%$ MUC5B positive epithelial cells, respectively (Fig. 5B and 5D). In 438 contrast, first-and second-generation airways from ozone-exposed males and females contained $439 \sim 83 \%$ and $\sim 61 \%$ MUC5B positive epithelial cells, respectively (Fig. 5C and 5D). The preterminal 440 and terminal bronchioles from air-exposed males and females had only $\sim 2 \%$ and $\sim 1 \%$ MUC5B 441 positive epithelial cells, respectively (Fig. 5E and 5G). On the other hand, the preterminal and 442 terminal bronchioles from ozone-exposed males and females had $\sim 55 \%$ and $\sim 67 \%$ MUC5B 443 positive epithelial cells, respectively (Fig. 5F and 5G). These data suggest that the enrichment of 444 MUC5B in the exosomal fraction from ozone-exposed mice is a result of the overproduction of 445 this protein in both large and small airways.

BALF exosomes carry proteins associated with homeostatic and perturbed lung environment

To identify the signaling pathways that are enriched within the exosomal proteins from airexposed mice, we performed Ingenuity pathway analysis (IPA) on the most abundant (top 10\%; 326 out of 3258 identified proteins) proteins. Abundance of proteins was determined by Log2 VSN normalized iBAQ MS1 intensities, i.e., proteins with highest intensity values were considered most abundant. We searched enrichment of pathways related to "molecular and cellular functions" and "Physiological system development and function" categories. Our analyses identified a number of pathways including protein synthesis, cellular movement, cell death and survival, molecular transport, tissue morphology, protein degradation, organismal development, immune cell trafficking, cellular assembly and organization, cellular function and maintenance, cellular compromise, cell-cell signaling and interaction, and hematological system development and function (Fig. 6A). Similarly, we performed IPA on the most abundant (top $10 \%$; 342 out of 3421 identified proteins) proteins in exosomes harvested from ozone-exposed mice. While most of the pathways, except for tissue morphology and protein degradation, that were enriched in the airexposed exosomes were also enriched in ozone-exposed exosomes, additional pathways identified

462 in ozone-exposed exosomes were RNA damage and repair, free-radical scavenging, lipid 463 metabolism, and small molecule biochemistry (Fig. 6B). These data show that BALF exosomes 
carry signatures of homeostatic lung environment as well as the diseased state.

Comparative analysis of proteins in BALF exosomes from ozone- vs air-exposed mice reveals enrichment of inflammation/injury associated pathways and protein interaction networks

Next, we analyzed disease-associated and functional pathways altered in the exosomes from ozone-exposed mice. Top enriched pathways included cellular compromise, inflammatory responses, cellular movement, immune cell trafficking, lipid metabolism, molecular transport, small molecular biochemistry, cell-cell interaction, hematological system development and function, immunological diseases, inflammatory diseases, respiratory diseases, cell death and survival, and free radical scavenging (Fig. 7A).

In order to determine the canonical pathways that are associated with the proteins that are enriched in the exosomes of ozone-exposed mice, we subjected differentially $(\mathrm{FC}>2, \mathrm{FDR}<0.05)$ expressed proteins (total,1255; enriched, 568; low-abundance, 687) in exosomes from ozoneexposed mice to pathway analysis using IPA application. Of the top 14 pathways, 9 were upregulated that included micropinocytosis, coagulation system, acute phase response, lipid antigen presentation by CD1, phagosome formation, leukocyte extravasation, calcium-induced $\mathrm{T}$ lymphocyte apoptosis, CTLA4 signaling in cytotoxic T lymphocytes, IL-3 signaling, GM-CSF signaling, and Oncostatin M signaling, and (Fig. 7B). Further, to identify the sex-dependent enrichment of canonical pathways, we performed a comparative analysis between differentially expressed signatures in ozone-exposed males (versus air-exposed males; 380, enriched; 438, lowabundance) and ozone-exposed females (versus air-exposed females; 427, enriched; 474, lowabundance). The analyses revealed a relatively higher z-score for the majority of pathways in ozone-exposed females versus ozone-exposed males (Fig. 7C and Supplemental Fig. 2).

487 Together, these analyses indicate ozone-induced stress within the airspaces that is reflected within the proteomic signatures of the exosomes present within these airspaces.

Next, to identify enriched protein-protein interaction (PPI) networks, we performed 491 mice. The significantly influenced PPI networks due to enriched exosomal protein signatures in 492 the BALF of ozone-exposed mice versus air-exposed mice included extracellular matrix (ECM) 493 organization, ECM-receptor interaction, cell junction organization, membrane trafficking, and 
neutrophil degranulation (Supplemental Fig. 3).

\section{Comparative analysis between enriched BALF exosomes proteins and previously published} upregulated gene signatures from ozone-exposed mice

In our recent publication ${ }^{17}$, we profiled transcriptomic changes from three distinct lung compartments from ozone-exposed mice. To determine whether the enriched protein signatures reflect upregulation of their transcripts, and to identify the potential source of exosomes carrying these proteins, we interrogated a list of significantly enriched exosomal proteins (568 identified proteins; FC $>2$; adj p-value $<0.05$ ) against the transcriptome from the airways, parenchyma, and macrophages. Each protein signature was used to extract fold-change and adj p-values from the three lung compartments. Transcriptomic signatures meeting cutoff criteria ( $\mathrm{FC}>1$; adj $\mathrm{p}$ value $<0.05$ ) from each tissue were considered significantly upregulated. We categorized the compartment-specific association of transcripts with exosomal protein signatures, based on the comparative analyses of gene expression changes across the three lung compartments.

Transcripts encoding 180 enriched protein signatures were upregulated in all three compartments (Table 5). Enrichment of 47 proteins was reflected in the upregulated DEGs from airways. Similarly, transcripts for 38 and 59 enriched proteins in the BALF exosomes were differentially upregulated exclusively in the parenchyma and the alveolar macrophages, respectively. Transcripts for 66 enriched proteins in the BALF exosomes were differentially upregulated in both airways and parenchyma. Similarly, transcripts for 44 and 63 enriched proteins in the BALF exosomes were differentially upregulated in extrapulmonary airways as well as airspace macrophages and parenchyma as well as alveolar macrophages, respectively. Finally, the enrichment of 71 proteins in the BALF exosomes did not reflect upregulated transcripts in any of the three compartments. 


\section{Discussion:}

525 Upon encountering abiotic and biotic inhaled insults, the resident lung cells, including 526 epithelial cells and macrophages, orchestrate intercellular communication dependent coordinated 527 responses to restore airspace homeostasis ${ }^{49}$. Apart from the classical mechanisms for intercellular 528 communication, i.e., direct cell-cell interaction or via soluble mediators, the exosomal cargo 529 biomolecules contribute to the intercellular communication across various physio-pathological 530 conditions $50,51,52$. Exosomes contain biologically active cargo including proteins, lipids, RNA, 531 and DNA that are known to modulate the functioning of the recipient or target cells ${ }^{53}$. These 532 biomolecular signatures also provide insights into the identity and the well-being of cells that 533 secrete these exosomes. Like most other cell types, lung epithelial cells and alveolar macrophages,

534 are known to release exosomes into their extracellular spaces ${ }^{3,14,15,52}$. In this study, we examined 535 the exosomal protein signatures in the airspaces of healthy as well as ozone-stressed lungs of mice. 536 To our knowledge, detailed proteomic analyses of exosomes in the ozone-exposed lungs have not 537 been conducted.

538 Here, we asked a series of questions including, 1) Which proteins are present in the 539 airspace-derived exosomes from healthy lungs (homeostasis)? 2) Whether the composition and the 540 abundance of exosomal proteins alter following ozone-exposure (stressed environment)? 3) What 541 biological pathways are influenced by the exosomal proteins during homeostasis and under 542 stressed environment? 4) Does the composition of the exosomal proteins reflect the 543 mucoinflammatory disturbances in the airspaces following ozone-induced stress? 5) What are the 544 likely contributors to the key inflammatory proteins in the airspaces following ozone-induced 545 stress? and 6) Whether it is possible to identify the cellular sources of proteins present within the 546 heterogenous population of airspace exosomes. We attempted to address these questions through 547 comprehensive exosomic-proteomic analyses, immunohistochemical staining, secretory protein 548 measurements, and comparative analyses between proteomic and transcriptomic signatures.

549 Under homeostatic conditions, epithelial cells and macrophages are known to 550 communicate with each other to restrict their proinflammatory characteristics ${ }^{54,55}$. This adaptive 551 phenomenon is critical in effectively curbing the exaggerated immune responses and disruption of 552 the gas exchange function of the respiratory tract. To address our first question, i.e., Which proteins 553 are present in the airspace-derived exosomes from healthy lungs, we analyzed the exosomes 554 harvested from the air-exposed males and females (Table 1). Club cell-specific protein (CCSP; 
also known as SCGB1A1 or uteroglobin), a product of club cells that possesses anti-inflammatory and immunosuppressive properties ${ }^{56,57}$, was the second most abundant protein present within the exosomes from air-exposed mice. Similarly, alveolar epithelial cell-derived pulmonary surfactant proteins (SFTPA, SFTPB, and SFTPD), also known to be immunosuppressive 58, 59, 60, were enriched within the exosomes from air-exposed mice. Other immunosuppressive proteins, MUC1 61, 62, 63, 64 and MUC5B ${ }^{65}$, products of mucous cells, were also recovered within the exosomes from air-exposed mice (data not shown). Antioxidant host defense system protects the cells of the respiratory mucosal surfaces from the reactive species generated from the relatively high concentration of inhaled oxygen $(\sim 150 \mathrm{mmHg}$ at sea level in the conducting airways and $\sim 100$ $\mathrm{mmHg}$ at sea level in the alveolar spaces) at basal levels ${ }^{66}$. Consistent with this, exosomes harvested from the air-exposed mice were enriched in antioxidant-response proteins including peroxiredoxin-6 (PRDX6), superoxide dismutase (SOD1), paraoxonase 1 (PON1), NADPHcytochrome P450 reductase (POR), Microsomal glutathione S-transferase 1 (MGST1), and Carbonyl reductase [NADPH] 2 (CBR2). These data indicate that exosomes harbor biomolecules critical for antioxidant defense mechanisms under homeostatic conditions. Together, our proteomic data from air-exposed exosomes suggest that, under homeostasis, exosomes carry protein signatures that are involved in anti-inflammatory responses and antioxidant defense.

Exposure to inhaled pollutants is known to induce airspace stress, increase the release rate of exosomes, and alter the composition of the exosomes ${ }^{67,68}$. Consistent with these reports, the total protein yield for exosomes was $\sim 2$ fold higher in ozone-exposed mice versus air-exposed mice. Approximately $16.4 \%$ of identified proteins (568 out of 3457) were significantly enriched in the exosomes from ozone-exposed mice versus air-exposed mice (Table 3; Figure 3F). Apart from this, 4.86\% (168 out of 3457) proteins (Histones, S100A8, Elastin, Laminins, FGBP1, MPO, FCGR3, Claudin4, 7, Calpain-6, SEMA3F) were found exclusively in the exosomes from ozoneexposed mice (Supplemental Table 3). Collectively, these data indicate that exposure to ozone not only significantly enhances the enrichment of exosomal proteins that were already present under homeostatic conditions, but also induces the secretion and transport of new proteins within the exosomes.

Ozone, being a highly oxidative gas, is known to cause oxidative stress ${ }^{69,70}$, therefore, an efficient antioxidant system is required to minimize the detrimental effects of reactive oxygen species. Interestingly, however, known antioxidant proteins (EPHX1, SOD1, GSTM1, PRDX6, 
PON1, MGST1, and POR) were significantly suppressed within the exosomes from ozoneexposed mice. Furthermore, the NRF2-mediated oxidative stress response pathway was also suppressed within the exosomes from ozone-exposed versus air-exposed mice. These findings are consistent with the previous reports that suggest that ozone exposure results in oxidative stress and a loss of NRF2 activation ${ }^{70}$.

While resident alveolar macrophages generally remain quiescent under homeostatic 592 conditions, their functionality is significantly enhanced upon stimulation by the 593 microenvironmental cues that are released by the adjoining cells within the stressed airspaces ${ }^{71}$. 594 Macrophage activation, i.e., enhanced functionality, is a known response to ozone inhalation ${ }^{17,40,}$ 59541,42 . Various macrophage activation markers including arginase 1 (ARG1), NOS2, Galectin 3 596 (LGALS3), and PTGS2 (COX2) have been reported to be increased in mice following acuteexposure to ozone $40,72,73,74$. Here, we hypothesized that the macrophage activation markers will 598 be enriched within the exosomes harvested from the ozone-exposed airspaces. Our analyses 599 revealed significant enrichment of the alternative activation markers within the exosomes of 600 ozone-exposed mice. For example, Galectin 3 (LGALS3), a carbohydrate-binding lectin, highly 601 expressed in the macrophages and epithelial cells, was upregulated in exosomes from ozone602 exposed mice. Galectin 3 expression promotes alternative macrophage activation. TGM2, a 603 member of the transglutaminase family of enzymes, that is known to promote alternative activation 604 of macrophages as well as clearance of apoptotic cells by macrophages (efferocytosis) ${ }^{75,76}$ was 605 also enriched in exosomes from ozone-exposed mice. Of note, TGM2 is a consistent marker of 606 alternative activation of macrophages in humans as well as in mice. Similarly, Resistin-like alpha 607 (RETNLA/FIZZ1), another robust marker of alternative activation of macrophages was 608 upregulated in exosomes from ozone-exposed mice. These data suggest that alternatively activated 609 macrophages from ozone-exposed airspaces release their signature proteins within the exosomes. 610 Interestingly, our histochemical analyses suggest that RETNLA protein expression is dramatically 611 upregulated in ozone-exposed airway epithelial (club) cells as well as macrophages, therefore, it 612 is unclear whether the exosomal RETNLA originates from both or one of the two cell types i.e. 613 macrophages and airway epithelial cells.

614 Enrichment of certain proteins within the exosomes from stressed airspaces may contribute 615 to the activation of functional and disease pathways. IP analyses on enriched proteins within the 616 exosomes from ozone-exposed mice revealed the activation of several canonical pathways 
617 including acute phase response signaling, leucocyte extravasation signaling, production of reactive 618 oxygen species by macrophages, micropinocytosis, phagosome formation, phagosome maturation, 619 lipid antigen presentation, GM-CSF signaling, and IL-3 signaling pathways. These data suggest 620 that the exosomes from ozone-exposed airspaces contain proteins that influence pathways relevant 621 to the inflammatory responses.

622 Ozone exposure results in the exacerbation of the respiratory symptoms in patients with 623 mucoinflammatory lung diseases such as COPD and asthma ${ }^{43,44,45}$. Exposure to high levels of 624 ozone for nearly a decade increases the susceptibility to the development of COPD ${ }^{77}$. Similarly, ozone exposure is associated with decline in lung function and increases in the levels of biomarkers 626 of airway inflammation in asthmatic patients ${ }^{78}$. To observe the effects of ozone exposure in 627 healthy mice and their likelihood of developing hallmarks of mucoinflammatory lung disease, we examined the enrichment of protein markers of mucoobstructive lung diseases within the exosomes from ozone-exposed mice. A large number of proteins that have been previously associated with the mucoobstructive lung diseases were enriched within the exosomes from ozoneexposed mice. These proteins include Galectin 3 (LGALS3), GCA, S100A9, Periostin (POSTN), MUC5AC, MUC5B, FGA, FGB, FGG, FN1, APOC1, IL1RN, and TOLLIP.

Previous reports have demonstrated that female mice show exaggerated inflammatory responses to ozone inhalation as compared to their male counterparts. In our recent report ${ }^{17}$, we also reported that, as compared to ozone-exposed males, ozone-exposed females exhibit exaggerated recruitment of inflammatory cells including macrophages, neutrophils, eosinophils, and lymphocytes. Consistent with cellular recruitment, the levels of total protein were also significantly elevated within the lungs of the ozone-exposed females versus ozone-exposed males.

639 Further, the inflammatory mediators including G-CSF, IL-5, and MIP1 $\beta$ were also significantly 640 elevated in ozone-exposed females versus air-exposed females (Fig. 1). Accordingly, we 641 hypothesized that the exosomes from ozone-exposed females either have significant enrichment 642 of proteins relevant to proinflammatory responses or a significant reduction in the abundance of 643 proteins relevant to anti-inflammatory responses. To our surprise, the total protein contents within 644 the harvested exosomes were comparable between ozone-exposed females and ozone-exposed 645 males. Increased total protein contents in cell-free BALF in ozone-exposed females is likely 646 attributable to the presence of a greater quantity of larger vesicles and cellular debris in ozone647 exposed females versus ozone-exposed males. From these data, we speculate that the rate of 
exosome shedding, a function of live cells, remains comparable between the ozone-exposed females and ozone-exposed males.

Regardless of the comparable amounts of total protein contents within the exosomes of the ozone-exposed male and female mice, exosomes from ozone-exposed females were different from those of the ozone-exposed males in multiple ways. First, although both ozone-exposed sexes shared enrichment of 263 proteins in their exosomes, exosomes from ozone-exposed females had an exclusive enrichment of 164 proteins as compared to 117 in ozone-exposed males (Fig. 3G-H). Second, in addition to 312 proteins that were suppressed upon ozone exposure in both sexes, additional 162 and 126 proteins were exclusively suppressed in ozone-exposed females and ozoneexposed males, respectively. Third, comparative analyses of the canonical pathways between ozone-exposed females and ozone-exposed males revealed higher z-scores in females (Fig. 7C and Supplemental Fig. 2). While these findings point towards an increased enrichment of airspace-relevant stress proteins in ozone-exposed females, the causal-effect relationship between exaggerated inflammatory responses and enrichment of inflammation-relevant exosomal proteins in females remains unexplored.

Identification of the cellular sources of exosomes within the lungs is often challenging because all the resident cells present within the airspaces are known to release exosomes. In exosomes from air-exposed mice, macrophage-specific (CHIL3, LYZ2), airway epithelial cellspecific (SCGB1A1), and alveolar epithelial cell-specific (SFTPA1, SFTPB, SFTPC) proteins were among the most abundant proteins. While these data suggest that, under steady-state, epithelial cells as well as macrophages actively release exosomes into the airspaces, the relative contribution of individual cell type towards the overall exosome populations in the airspaces remains challenging to determine. Proteins including Histones, Annexins, S100s, RETNLA that were relatively less abundant in exosomes from air-exposed mice were highly abundant in exosomes from ozone-exposed mice suggesting the increased release of these proteins in ozoneexposed airspaces. We hypothesized that the exosomal enrichment of these proteins is contributed by the cellular compartment that overexpresses their respective transcripts. Accordingly, comparative analyses between exosomal proteins and their respective transcripts from the three compartments (airway, parenchyma, macrophages) revealed interesting findings. Transcript levels of the enriched exosomic proteins including histones, RETNLA, Annexins, and S100s were elevated in more than one compartment, if not all three. These data suggest that the ozone 
679 stimulates the release of certain proteins from multiple cellular types.

680 In conclusion, this study reveals various interesting findings. First, under unchallenged 681 conditions, resident cells shed exosomes that contain protein signatures relevant to homeostasis, 682 cell-specificity, and antioxidant defense. Second, ozone-exposure contributes to a significant 683 enrichment of those proteins within the exosomes that were present under the homeostatic state. 684 Third, ozone-exposure, in addition, stimulates the release of stress-related proteins within the 685 exosomes. Fourth, proteins enriched within the exosomes from ozone-exposed mice represent 686 activation of pathways associated with stress-response. Fifth, comparative analyses of the 687 exosomes from ozone-exposed mice identified sex-specific protein signatures. This is was also 688 true for the secretory proteins present within the cell-free BALF following ozone-exposure. Sixth, 689 cellular localization of selected muco-inflammatory disease-related proteins revealed the potential 690 cellular contributors of these proteins in the exosomal compartment following ozone-exposure. 691 Finally, comparative analyses between the exosomal proteins and the lung compartment-specific 692 transcriptomic-signatures revealed compartment-specific contribution towards exosomal protein 693 contents. Collectively, this study presents detailed proteomic analyses of exosomes from 694 homeostatic and ozone-stressed airspaces in mice. These data will aid in future mechanistic studies 695 to unravel underlying inflammation-relevant pathways in ozone-exposed lungs. 


\section{Acknowledgments}

711 We thank Thaya Stoufflet for assistance with multiplex cytokine assays. We thank Sherry Ring

712 for histological tissue processing. We thank Dr. Camille Ehre (University of North Carolina at

713 Chapel Hill) for providing MUC5B antibody.

714

715 Author Contributions

716 Y.S. conceived and designed the research; I.C., T.V., K.P., and Y. S. maintained the animal colony,

717 performed ozone exposures, conducted animal necropsies, and performed cytokine measurement

718 experiments; I.C. harvested exosomes. K.P. and Y.S. performed the immunohistochemical

719 analysis. M.K. and R.G. performed exosome analyses. S.P. and Y.S. analyze the histopathological

720 and immunohistochemical data; S.P. and Y.S. wrote and reviewed the manuscript for intellectual 721 contents.

722 Disclosures: The authors have no conflicts of interest to disclose.

723

724

725

726

727

728

729

730

731

732

733

734

735

736

737

738

739 


\section{References:}

742 1. Colombo, M., Raposo, G. \& Thery, C. Biogenesis, secretion, and intercellular interactions 743 of exosomes and other extracellular vesicles. Annu Rev Cell Dev Biol 30, 255-289 (2014).

2. Thery, C., Zitvogel, L. \& Amigorena, S. Exosomes: composition, biogenesis and function. Nat Rev Immunol 2, 569-579 (2002).

3. McVey, M.J., Maishan, M., Blokland, K.E.C., Bartlett, N. \& Kuebler, W.M. Extracellular vesicles in lung health, disease, and therapy. Am J Physiol Lung Cell Mol Physiol 316,

$750 \quad$ L977-L989 (2019).

4. Muller, L., Hong, C.S., Stolz, D.B., Watkins, S.C. \& Whiteside, T.L. Isolation of biologicallyactive exosomes from human plasma. J Immunol Methods 411, 55-65 (2014).

5. Grant, R. et al. A filtration-based protocol to isolate human plasma membrane-derived vesicles and exosomes from blood plasma. J Immunol Methods 371, 143-151 (2011).

6. Torregrosa Paredes, P. et al. Bronchoalveolar lavage fluid exosomes contribute to cytokine and leukotriene production in allergic asthma. Allergy 67, 911-919 (2012).

7. Admyre, C. et al. Exosomes with major histocompatibility complex class II and costimulatory molecules are present in human BAL fluid. Eur Respir J 22, 578-583 (2003).

8. Pisitkun, T., Shen, R.F. \& Knepper, M.A. Identification and proteomic profiling of exosomes in human urine. Proc Natl Acad Sci U S A 101, 13368-13373 (2004).

9. Gonzales, P.A. et al. Isolation and purification of exosomes in urine. Methods Mol Biol

10. Chanteloup, G. et al. Monitoring HSP70 exosomes in cancer patients' follow up: a clinical prospective pilot study. J Extracell Vesicles 9, 1766192 (2020).

772

773

774

11. Amiri, A. et al. Exosomes and Lung cancer: Roles in pathophysiology, diagnosis and therapeutic applications. Curr Med Chem (2020). 
12. McVey, M.J., Spring, C.M., Semple, J.W., Maishan, M. \& Kuebler, W.M. Microparticles as biomarkers of lung disease: enumeration in biological fluids using lipid bilayer microspheres. Am J Physiol Lung Cell Mol Physiol 310, L802-814 (2016).

779

780

781

782

783

784

785

786

787

788

789

790

791

792

793

794

795

796

797

798

799

800

801

802

803

804

805

806

807

808

809

810
13. Mathieu, M., Martin-Jaular, L., Lavieu, G. \& Thery, C. Specificities of secretion and uptake of exosomes and other extracellular vesicles for cell-to-cell communication. Nat Cell Biol 21, 9-17 (2019).

14. Wahlund, C.J.E., Eklund, A., Grunewald, J. \& Gabrielsson, S. Pulmonary Extracellular Vesicles as Mediators of Local and Systemic Inflammation. Front Cell Dev Biol 5, 39 (2017).

15. Andres, J. et al. Role of extracellular vesicles in cell-cell communication and inflammation following exposure to pulmonary toxicants. Cytokine Growth Factor Rev 51, 12-18 (2020).

16. Lee, H., Zhang, D., Laskin, D.L. \& Jin, Y. Functional Evidence of Pulmonary Extracellular Vesicles in Infectious and Noninfectious Lung Inflammation. J Immunol 201, 1500-1509 (2018).

17. Choudhary, I., Vo, T., Paudel, K., Patial, S., Saini, Y. Compartment-specific transcriptomics of ozone-exposed murine lungs reveals sex and cell type-associated perturbations relevant to mucoinflammatory lung diseases. American Journal of Lung Cellular and Molecular Physiology Accepted (ahead of Print) (2020).

18. Hatch, G.E. et al. Progress in Assessing Air Pollutant Risks from In Vitro Exposures: Matching Ozone Dose and Effect in Human Airway Cells. Toxicological Sciences 141, 198205 (2014).

19. Hatch, G.E. et al. Biomarkers of Dose and Effect of Inhaled Ozone in Resting versus Exercising Human Subjects: Comparison with Resting Rats. Biomark Insights 8, 53-67 (2013).

811 
812 21. Cabello, N. et al. Sex differences in the expression of lung inflammatory mediators in response to ozone. American Journal of Physiology-Lung Cellular and Molecular Physiology 309, L1150-L1163 (2015).

22. Birukova, A. et al. Sex Modifies Acute Ozone-Mediated Airway Physiologic Responses.

23. Tashiro, H. et al. Sex Differences in the Impact of Dietary Fiber on Pulmonary Responses to Ozone. Am J Respir Cell Mol Biol 62, 503-512 (2020).

24. Cho, Y. et al. Sex Differences in Pulmonary Responses to Ozone in Mice. Role of the Microbiome. Am J Respir Cell Mol Biol 60, 198-208 (2019).

25. Peirson, S.N. \& Foster, R.G. Bad light stops play. EMBO Rep 12, 380 (2011).

26. Thery, C., Amigorena, S., Raposo, G. \& Clayton, A. Isolation and characterization of exosomes from cell culture supernatants and biological fluids. Curr Protoc Cell Biol Chapter 3, Unit 322 (2006).

27. Nesvizhskii, A.I., Keller, A., Kolker, E. \& Aebersold, R. A statistical model for identifying proteins by tandem mass spectrometry. Anal Chem 75, 4646-4658 (2003).

28. Huber, W., von Heydebreck, A., Sultmann, H., Poustka, A. \& Vingron, M. Variance stabilization applied to microarray data calibration and to the quantification of differential expression. Bioinformatics 18 Suppl 1, S96-104 (2002).

29. Bolstad, B.M. PreprocessCore: A collection of pre-processing functions. $R$ package version 1.48.0. (2019). normalization methods for omics data sets. J Proteome Res 13, 3114-3120 (2014). 
32. Alhamdoosh, M. et al. Easy and efficient ensemble gene set testing with EGSEA. F1000Res 6, 2010 (2017).

33. Szklarczyk, D. et al. STRING v11: protein-protein association networks with increased coverage, supporting functional discovery in genome-wide experimental datasets. Nucleic Acids Res 47, D607-D613 (2019).

35. Lewis, B.W. et al. The Innate Lymphoid System Is a Critical Player in the Manifestation of

34. Lewis, B.W. et al. Ablation of IL-33 Suppresses Th2 Responses but Is Accompanied by Sustained Mucus Obstruction in the Scnn1b Transgenic Mouse Model. J Immunol 204, 1650-1660 (2020).

860

36. Nadadur, S.S., Costa, D.L., Slade, R., Silbjoris, R. \& Hatch, G.E. Acute Ozone-Induced Differential Gene Expression Profiles in Rat Lung. Environmental Health Perspectives 113, 1717-1722 (2005).

864

38. Joyner, B.L. et al. DNA and inflammatory mediators in bronchoalveolar lavage fluid from children with acute inhalational injuries. J Burn Care Res 34, 326-333 (2013).

39. Kirchner, K.K., Wagener, J.S., Khan, T.Z., Copenhaver, S.C. \& Accurso, F.J. Increased DNA levels in bronchoalveolar lavage fluid obtained from infants with cystic fibrosis. Am J Respir Crit Care Med 154, 1426-1429 (1996).

40. Sunil, V.R., Patel-Vayas, K., Shen, J., Laskin, J.D. \& Laskin, D.L. Classical and alternative macrophage activation in the lung following ozone-induced oxidative stress. Toxicol Appl Pharmacol 263, 195-202 (2012).

41. Groves, A.M. et al. Age-related increases in ozone-induced injury and altered pulmonary mechanics in mice with progressive lung inflammation. Am J Physiol Lung Cell Mol Physiol 305, L555-568 (2013). 
42. Mathews, J.A. et al. gammadelta T Cells Are Required for M2 Macrophage Polarization and Resolution of Ozone-Induced Pulmonary Inflammation in Mice. PLoS One 10, e0131236 (2015).

43. McDonnell, W.F., Abbey, D.E., Nishino, N. \& Lebowitz, M.D. Long-term ambient ozone concentration and the incidence of asthma in nonsmoking adults: the AHSMOG Study. Environ Res 80, 110-121 (1999).

44. Anenberg, S.C. et al. Estimates of the Global Burden of Ambient [Formula: see text], Ozone, and [Formula: see text] on Asthma Incidence and Emergency Room Visits. Environ Health Perspect 126, 107004 (2018).

45. Tetreault, L.F. et al. Childhood Exposure to Ambient Air Pollutants and the Onset of Asthma: An Administrative Cohort Study in Quebec. Environ Health Perspect 124, 12761282 (2016).

46. Strosnider, H.M. et al. Age-Specific Associations of Ozone and Fine Particulate Matter with Respiratory Emergency Department Visits in the United States. Am J Respir Crit Care Med 199, 882-890 (2019).

47. Paulin, L.M., Kaufman, J.D. \& Hansel, N.N. Concerns Remain Regarding Long-term Ozone Exposure and Respiratory Outcomes-Reply. JAMA Intern Med (2020).

48. Kirkham, S. et al. MUC5B is the major mucin in the gel phase of sputum in chronic obstructive pulmonary disease. Am J Respir Crit Care Med 178, 1033-1039 (2008).

49. Boitano, S., Safdar, Z., Welsh, D.G., Bhattacharya, J. \& Koval, M. Cell-cell interactions in regulating lung function. Am J Physiol Lung Cell Mol Physiol 287, L455-459 (2004).

50. Gupta, R. et al. Intercellular Communication between Airway Epithelial Cells Is Mediated by Exosome-Like Vesicles. Am J Respir Cell Mol Biol 60, 209-220 (2019).

51. Lee, H., Abston, E., Zhang, D., Rai, A. \& Jin, Y. Extracellular Vesicle: An Emerging Mediator of Intercellular Crosstalk in Lung Inflammation and Injury. Front Immunol 9, 924 (2018). 
52. Moon, H.G. et al. Lung epithelial cell-derived extracellular vesicles activate macrophagemediated inflammatory responses via ROCK1 pathway. Cell Death Dis 6, e2016 (2015).

921

922
53. Yanez-Mo, M. et al. Biological properties of extracellular vesicles and their physiological functions. J Extracell Vesicles 4, 27066 (2015).

54. Haggadone, M.D. \& Peters-Golden, M. Microenvironmental Influences on Extracellular Vesicle-Mediated Communication in the Lung. Trends Mol Med 24, 963-975 (2018).

55. Fujita, Y., Kosaka, N., Araya, J., Kuwano, K. \& Ochiya, T. Extracellular vesicles in lung microenvironment and pathogenesis. Trends Mol Med 21, 533-542 (2015).

56. Levin, S.W., Butler, J.D., Schumacher, U.K., Wightman, P.D. \& Mukherjee, A.B. Uteroglobin inhibits phospholipase A2 activity. Life Sci 38, 1813-1819 (1986).

57. Hayashida, S., Harrod, K.S. \& Whitsett, J.A. Regulation and function of CCSP during pulmonary Pseudomonas aeruginosa infection in vivo. Am J Physiol Lung Cell Mol Physiol 279, L452-459 (2000).

58. Rosseau, S. et al. Surfactant protein A down-regulates proinflammatory cytokine production evoked by Candida albicans in human alveolar macrophages and monocytes. J Immunol 163, 4495-4502 (1999).

59. Ikegami, M. et al. Surfactant protein-D and surfactant inhibit endotoxin-induced pulmonary inflammation. Chest 132, 1447-1454 (2007).

60. Allen, J.N., Moore, S.A., Pope-Harman, A.L., Marsh, C.B. \& Wewers, M.D. Immunosuppressive properties of surfactant and plasma on alveolar macrophages. $J$ Lab Clin Med 125, 356-369 (1995).

61. Ueno, K. et al. MUC1 mucin is a negative regulator of toll-like receptor signaling. Am J Respir Cell Mol Biol 38, 263-268 (2008).

62. Sheng, Y.H. et al. MUC1 and MUC13 differentially regulate epithelial inflammation in response to inflammatory and infectious stimuli. Mucosal Immunol 6, 557-568 (2013). 
63. Li, Y., Dinwiddie, D.L., Harrod, K.S., Jiang, Y. \& Kim, K.C. Anti-inflammatory effect of MUC1 during respiratory syncytial virus infection of lung epithelial cells in vitro. Am J Physiol Lung Cell Mol Physiol 298, L558-563 (2010).

64. Guang, W. et al. Muc1 cell surface mucin attenuates epithelial inflammation in response to a common mucosal pathogen. J Biol Chem 285, 20547-20557 (2010).

65. Roy, M.G. et al. Muc5b is required for airway defence. Nature 505, 412-416 (2014).

66. Cantin, A.M., Fells, G.A., Hubbard, R.C. \& Crystal, R.G. Antioxidant macromolecules in the epithelial lining fluid of the normal human lower respiratory tract. J Clin Invest 86, 962-971 (1990).

67. Lee, H., Zhang, D., Wu, J., Otterbein, L.E. \& Jin, Y. Lung Epithelial Cell-Derived Microvesicles Regulate Macrophage Migration via MicroRNA-17/221-Induced Integrin beta1 Recycling. J Immunol 199, 1453-1464 (2017).

68. Bourdonnay, E. et al. Transcellular delivery of vesicular SOCS proteins from macrophages to epithelial cells blunts inflammatory signaling. J Exp Med 212, 729-742 (2015).

69. Mudway, I.S. et al. Compromised concentrations of ascorbate in fluid lining the respiratory tract in human subjects after exposure to ozone. Occup Environ Med 56, 473-481 (1999).

70. Wiegman, C.H. et al. A comprehensive analysis of oxidative stress in the ozone-induced lung inflammation mouse model. Clin Sci (Lond) 126, 425-440 (2014).

71. Mosser, D.M. \& Edwards, J.P. Exploring the full spectrum of macrophage activation. Nat Rev Immunol 8, 958-969 (2008).

72. Sunil, V.R. et al. Regulation of ozone-induced lung inflammation and injury by the betagalactoside-binding lectin galectin-3. Toxicol Appl Pharmacol 284, 236-245 (2015).

73. Sunil, V.R. et al. Ozone-induced injury and oxidative stress in bronchiolar epithelium are associated with altered pulmonary mechanics. Toxicol Sci 133, 309-319 (2013). 
992 74. Cabello, N. et al. Sex differences in the expression of lung inflammatory mediators in 993 response to ozone. Am J Physiol Lung Cell Mol Physiol 309, L1150-1163 (2015).

994

995 75. Martinez, F.O. et al. Genetic programs expressed in resting and IL-4 alternatively activated mouse and human macrophages: similarities and differences. Blood 121, e5769 (2013).

998

76. Eligini, S., Fiorelli, S., Tremoli, E. \& Colli, S. Inhibition of transglutaminase 2 reduces efferocytosis in human macrophages: Role of CD14 and SR-Al receptors. Nutr Metab Cardiovasc Dis 26, 922-930 (2016).

1002

1003

77. Paulin, L.M. et al. Association of Long-term Ambient Ozone Exposure With Respiratory Morbidity in Smokers. JAMA Intern Med (2019).

1005

1006

1007

78. Khatri, S.B. et al. Association of ambient ozone exposure with airway inflammation and allergy in adults with asthma. J Asthma 46, 777-785 (2009).

1008

1009 
Table 1:

\begin{tabular}{|c|c|c|c|c|c|c|c|}
\hline \multicolumn{4}{|c|}{ Exosomal Proteins Enriched in Air-exposed mice } & \multicolumn{4}{|c|}{ Exosomal Proteins Enriched in Ozone-exposed mice } \\
\hline \multirow[b]{2}{*}{ Protein } & \multirow[b]{2}{*}{ Description } & \multicolumn{2}{|c|}{ Ranking in } & \multirow[b]{2}{*}{ Protein } & \multirow[b]{2}{*}{ Description } & \multicolumn{2}{|c|}{ Ranking in } \\
\hline & & \begin{tabular}{|l|l|} 
Air \\
\end{tabular} & Ozone & & & Ozone & Air \\
\hline ALB & Serum albumin & 1 & 1 & ALB & Serum albumin & 1 & 1 \\
\hline SCGB1A1 & Uteroglobin & 2 & 3 & HIST1H4A & Histone H4 & 2 & 126 \\
\hline TF & Serotransferrin & 3 & 8 & SCGB1A1 & Uteroglobin & 3 & 2 \\
\hline SFTPD & Pulmonary surfactant-associated protein D & 4 & 5 & HIST1H2B & Histone $\mathrm{H} 2 \mathrm{~B}$ & 4 & 324 \\
\hline$\pi R$ & Transthyretin & 5 & 12 & SFTPD & Pulmonary surfactant-associated protein D & 5 & 4 \\
\hline SFTPA1 & Pulmonary surfactant-associated protein A & 6 & 9 & ACTB & Actin, cytoplasmic 1 & 6 & 9 \\
\hline CYP2F2 & Cytochrome P450 2F2 & 7 & 36 & HIST1H2A & Histone $\mathrm{H} 2 \mathrm{~A}$ & 7 & 381 \\
\hline CES1D & Carboxylesterase 1D & 8 & 29 & TF & Serotransferrin & 8 & 3 \\
\hline ACTB & Actin, cytoplasmic 1 & 9 & 6 & SFTPA1 & Pulmonary surfactant-associated protein $\mathrm{A}$ & 9 & 6 \\
\hline PRDX6 & Peroxiredoxin-6 & 10 & 11 & H3F3A & Histone H3.2; Histone H3 & 10 & 376 \\
\hline PRSS1 & Cationic Trypsinogen & 11 & 26 & PRDX6 & Peroxiredoxin-6 & 11 & 10 \\
\hline AHSG & Alpha-2-HS-glycoprotein & 12 & 16 & $\pi R$ & Transthyretin & 12 & 5 \\
\hline $\mathrm{HP}$ & Haptoglobin & 13 & 20 & TRY4;TRY5 & Trypsin 4;5 & 13 & 72 \\
\hline $\mathrm{HPX}$ & Hemopexin & 14 & 24 & GPRC5A & Retinoic acid-induced protein 3 & 14 & 29 \\
\hline LYZ2 & Lysozyme C-2 & 15 & 82 & BPIFB1 & BPI fold-containing family B member 1 & 15 & 20 \\
\hline ALDH1A1 & Retinal dehydrogenase 1 & 16 & 22 & AHSG & Alpha-2-HS-glycoprotein & 16 & 12 \\
\hline CHIL3 & Chitinase-like protein 3 & 17 & 67 & ANXA5 & Annexin A5 & 17 & 36 \\
\hline CYB5A & Cytochrome b5 & 18 & 53 & RPS27A & Ubiquitin-40S ribosomal protein $\mathrm{S} 27 \mathrm{a}$ & 18 & 40 \\
\hline SERPINA1E & Alpha-1-antitrypsin 1-5 & 19 & 34 & APOA4 & Apolipoprotein A-IV & 19 & 27 \\
\hline BPIFB1 & BPI fold-containing family B member 1 & 20 & 15 & $\mathrm{HP}$ & Haptoglobin & 20 & 13 \\
\hline HBA & Hemoglobin subunit alpha & 21 & 39 & HIST1H1C & Histone H1.2 & 21 & 382 \\
\hline SOD1 & Superoxide dismutase [Cu-Zn] & 22 & 41 & ALDH1A1 & Retinal dehydrogenase 1 & 22 & 16 \\
\hline CHI3L1 & Chitinase-3-like protein 1 & 23 & 109 & SEC14L3 & SEC14 like Lipid Binding 3 & 23 & 32 \\
\hline SELENBP1;2 & Selenium-binding protein $1 ; 2$ & 24 & 27 & HPX & Hemopexin & 24 & 14 \\
\hline SERPINA1D & Alpha-1-antitrypsin 1-4 & 25 & 25 & SERPINA1D & Alpha-1-antitrypsin 1-4 & 25 & 25 \\
\hline CES1C & Carboxylesterase 1C & 26 & 50 & PRSS1 & Cationic Trypsinogen & 26 & 11 \\
\hline APOA4 & Apolipoprotein A-IV & 27 & 19 & SELENBP1;2 & Selenium-binding protein $1 ; 2$ & 27 & 24 \\
\hline HBB-BS & Hemoglobin subunit beta-1 & 28 & 54 & GSN & Gelsolin & 28 & 37 \\
\hline GPRC5A & Retinoic acid-induced protein 3 & 29 & 14 & CES1D & Carboxylesterase 1D & 29 & 8 \\
\hline PON1 & Serum paraoxonase/arylesterase 1 & 30 & 104 & ANXA1 & Annexin A1 & 30 & 102 \\
\hline SFTPB & Pulmonary surfactant-associated protein B & 31 & 78 & MSN & Moesin & 31 & 39 \\
\hline SEC14L3 & SEC14 like Lipid Binding 3 & 32 & 23 & CALM1 & Calmodulin 1 & 32 & 48 \\
\hline METTL7A1 & Methyltransferase-like protein 7A & 33 & 144 & ANXA2 & Annexin A2;Annexin & 33 & 70 \\
\hline POR & NADPH--cytochrome P450 reductase & 34 & 103 & SERPINA1E & Alpha-1-antitrypsin 1-5 & 34 & 19 \\
\hline SERPINA1B & Alpha-1-antitrypsin 1-2 & 35 & 76 & CD36 & Platelet glycoprotein 4 & 35 & 44 \\
\hline ANXA5 & Annexin A5 & 36 & 17 & CYP2F2 & Cytochrome P450 2F2 & 36 & 7 \\
\hline GSN & Gelsolin & 37 & 28 & ANXA3 & Annexin A3 & 37 & 63 \\
\hline CBR2 & Carbonyl reductase [NADPH] 2 & 38 & 40 & SDCBP & Syntenin-1 & 38 & 113 \\
\hline MSN & Moesin & 39 & 31 & HBA & Hemoglobin subunit alpha & 39 & 21 \\
\hline RPS27A & Ubiquitin-40S ribosomal protein $\mathrm{S} 27 \mathrm{a}$ & 40 & 18 & CBR2 & Carbonyl reductase [NADPH] 2 & 40 & 38 \\
\hline FTL1;FTL2 & Ferritin & 41 & 83 & SOD1 & Superoxide dismutase [Cu-Zn] & 41 & 22 \\
\hline MGST1 & Microsomal glutathione S-transferase 1 & 42 & 131 & APOA1 & Apolipoprotein A-I & 42 & 91 \\
\hline FTH1 & Ferritin heavy chain & 43 & 66 & AQP5 & Aquaporin-5 & 43 & 79 \\
\hline CD36 & Platelet glycoprotein 4 & 44 & 35 & S100A11 & Protein S100-A11 & 44 & 110 \\
\hline IGHG2B & Ig gamma-2B chain C region & 45 & 101 & S100A6 & Protein S100-A6 & 45 & 96 \\
\hline $\mathrm{P} 4 \mathrm{HB}$ & Protein disulfide-isomerase & 46 & 141 & RETNLA & Resistin-like alpha & 46 & 367 \\
\hline TUBB4B; 4A & Tubulin beta-4B chain; 4A chain & 47 & 47 & TUBB4B;4A & Tubulin beta-4B chain; 4A chain & 47 & 47 \\
\hline CALM1 & Calmodulin 1 & 48 & 32 & HSPA8 & Heat shock cognate $71 \mathrm{kDa}$ protein & 48 & 82 \\
\hline SERPINC1 & Antithrombin-III & 49 & 84 & RHOA & Transforming protein RhoA & 49 & 68 \\
\hline C5 & Complement C5 & 50 & 151 & CES1C & Carboxylesterase $1 \mathrm{C}$ & 50 & 26 \\
\hline
\end{tabular}

Table 1: Top 50 protein signatures enriched in air- and ozone-exposed mice. Ranking column on the right of Air (or Ozone) column indicates the ranking of the protein in the ozone (or air) group. Red text indicate that the corresponding protein is not present in top 50 in the respective exposure group. 
Table 2A: Top Differentially expressed protein signatures between air-exposed females and air-exposed males.

\begin{tabular}{|l|l|r|r|}
\hline \multicolumn{1}{|c|}{ Protein } & \multicolumn{1}{|c|}{ Description } & \multicolumn{1}{|c|}{ FC } & \multicolumn{1}{c|}{ adj.P.Val } \\
\hline Upregulated & \multicolumn{1}{|c|}{} & \\
\hline SIPA1L3 & Signal-induced proliferation-associated 1-like protein 3 & 112.60 & $4.0 E-07$ \\
\hline CDCP1 & CUB domain-containing protein 1 & 56.22 & 0.0306 \\
\hline HECTD1 & E3 ubiquitin-protein ligase HECTD1 & 11.09 & 0.0306 \\
\hline CGN & Cingulin & 8.07 & 0.0137 \\
\hline NA & Ig kappa chain V-III region PC 3741/TEPC 111; lg kappa chain V-III region TEPC & 3.92 & 0.0361 \\
\hline & & & \\
\hline Downregulated & & & \\
\hline PTPN23 & Tyrosine-protein phosphatase non-receptor type 23 & -424.61 & 0.0000 \\
\hline MUP20 & Major urinary protein 20 & -40.28 & 0.0001 \\
\hline MUP4, 6, 8, 9, 19 & Major urinary protein 4, 6, 8, 9, 19 & -29.90 & 0.0001 \\
\hline CLIP1 & CAP-Gly domain-containing linker protein 1 & -9.45 & 0.0383 \\
\hline WNK1 & Serine/threonine-protein kinase WNK1 & -7.51 & 0.0306 \\
\hline MUP10; MUP1 & Major urinary protein 10 & -4.84 & 0.0306 \\
\hline C8G & Complement component C8 gamma chain & -4.34 & 0.0511 \\
\hline CFL2 & Cofilin-2 & -4.07 & 0.0383 \\
\hline SERPINA1E & Alpha-1-antitrypsin 1-5 & -3.99 & 0.0306 \\
\hline CDK16, 17, 18 & Cyclin-dependent kinase 16, 17, 18 & -3.06 & 0.0383 \\
\hline
\end{tabular}

Table 2B: Top Differentially expressed protein signatures between ozone-exposed females and ozoneexposed males.

\begin{tabular}{|l|l|r|r|}
\hline \multicolumn{1}{|c|}{ Ozone-exposed Females vs Ozone-exposed Males } & \multicolumn{1}{|c|}{ FC } & adj.P.Val \\
\hline \multicolumn{1}{|c|}{ Protein } & \multicolumn{1}{|c|}{ Description } & \\
\hline Upregulated & \multicolumn{1}{|c|}{} & \multicolumn{1}{|c|}{} \\
\hline CD5L & CD5 antigen-like & 8.75 & 0.0471 \\
\hline VAMP5 & Vesicle-associated membrane protein 5 & 8.51 & 0.0417 \\
\hline MSLN & Mesothelin; Megakaryocyte-potentiating factor; Mesothelin, cleaved form & 4.72 & 0.0417 \\
\hline NA & Ig kappa chain V-III region PC 3741/TEPC 111; Ig kappa chain V-III region TEPC & 3.89 & 0.0471 \\
\hline LTF & Lactotransferrin & 3.56 & 0.0482 \\
\hline & & & \\
\hline CDK17; CDK18; & & & \\
\hline H3F3C; H3F3A & Histone H3.3C;Histone H3.3;Histone H3 & -73.52 & 0.0021 \\
\hline MUP4; MUP9; & Major urinary protein 6; Major urinary proteins 11 and 8 & -29.65 & 0.0002 \\
\hline MUP20 & Major urinary protein 20 & -14.52 & 0.0046 \\
\hline CFAP20 & Cilia- and flagella-associated protein 20 & -12.13 & 0.0417 \\
\hline PRKAR2B & cAMP-dependent protein kinase type II-beta regulatory subunit & -4.66 & 0.0404 \\
\hline AKAP2; PAKAP & A-kinase anchor protein 2 & -3.71 & 0.0533 \\
\hline
\end{tabular}


Table 3: Top 50 protein signatures that were enriched in ozone-exposed mice versus air-exposed mice.

\begin{tabular}{|c|c|c|c|c|c|c|c|c|c|c|}
\hline \multicolumn{5}{|c|}{ Common in Both Genders } & \multicolumn{3}{|c|}{ Unique to Males } & \multicolumn{3}{|c|}{ Unique to Females } \\
\hline Protein & FC (Male) & adj.P.Val (Males) & FC (Females) & adj.P.Val (Females) & Protein & \begin{tabular}{|l|} 
FC \\
\end{tabular} & adj.P.Val & Protein & FC & adj.P.Val \\
\hline H1F0 & 366.00 & 0.0021 & 87.75 & 0.0061 & CDCP1 & 68.53 & 0.0012 & PTPN23 & 185.25 & $9.81 \mathrm{E}-06$ \\
\hline EPHA2 & 235.79 & 0.0004 & 89.75 & 0.0002 & SIPA1L3 & 29.20 & 0.0000 & CD151 & 59.59 & 0.0011 \\
\hline H3F3A & 212.11 & 0.0000 & 4.77 & 0.0268 & ITGB6 & 21.11 & 0.0029 & CHMP2A & 30.31 & 0.0356 \\
\hline HIST1H1B & 177.60 & 0.0000 & 43.06 & 0.0000 & STX4 & 18.14 & 0.0369 & APOD & 17.85 & 0.0030 \\
\hline H2AFJ & 169.82 & 0.0000 & 117.94 & 0.0000 & PRPF8 & 13.15 & 0.0085 & DLG1 & 17.29 & 0.0197 \\
\hline HIST1H1E & 104.76 & 0.0000 & 54.44 & 0.0001 & SNRPN & 13.01 & 0.0089 & SLC6A6 & 14.66 & 0.0115 \\
\hline H2AFY & 103.52 & 0.0004 & 43.86 & 0.0009 & ARFGEF2 & 11.93 & 0.0059 & CKMT1 & 12.03 & 0.0057 \\
\hline HIST1H2BR & 97.76 & 0.0000 & 92.89 & 0.0000 & HNRNPA1 & 11.68 & 0.0100 & PLA2G7 & 11.14 & 0.0038 \\
\hline HIST1H3A & 95.05 & 0.0002 & 77.01 & 0.0006 & HSPA2 & 10.71 & 0.0036 & CHMP1B & 10.32 & 0.0094 \\
\hline GP2 & 75.59 & 0.0012 & 58.81 & 0.0011 & TARDBP & 10.36 & 0.0181 & RPL35A & 10.28 & 0.0437 \\
\hline HIST1H3B & 72.74 & 0.0000 & 127.66 & 0.0000 & PTGS2 & 10.11 & 0.0523 & PLAUR & 10.26 & 0.0099 \\
\hline TNC & 68.46 & 0.0206 & 73.58 & 0.0069 & TRIM28 & 9.71 & 0.0037 & GLUD1 & 9.71 & 0.0127 \\
\hline HIST1H1C & 65.82 & 0.0000 & 32.16 & 0.0001 & FBL & 9.16 & 0.0055 & MMP10 & 9.60 & 0.0214 \\
\hline HIST1H4A & 62.93 & 0.0000 & 63.08 & 0.0000 & $\mathrm{NCL}$ & 8.12 & 0.0168 & MYO18A & 9.08 & 0.0038 \\
\hline CKAP5 & 62.45 & 0.0012 & 41.38 & 0.0026 & LSR & 7.67 & 0.0044 & PIP5K1A & 8.93 & .0075 \\
\hline HIST1H1D & 38.31 & 0.0000 & 16.95 & 0.0002 & RBBP7 & 7.58 & 0.0087 & RFTN1 & 8.78 & 0.0271 \\
\hline SDCBP2 & 31.76 & 0.0028 & 51.70 & 0.0012 & COL4A3BP & 7.24 & 0.0029 & TSPO & 8.71 & 0.0164 \\
\hline SNRPD1 & 25.93 & 0.0016 & 22.95 & 0.0014 & EIF2B5 & 7.18 & 0.0033 & CHMP5 & 7.08 & 0.0117 \\
\hline EFTUD2 & 25.11 & 0.0007 & 25.33 & 0.0026 & MAP4 & 6.55 & 0.0047 & RALBP1 & 6.80 & 0.0408 \\
\hline LLGL2 & 24.69 & 0.0000 & 19.85 & 0.0000 & LRRC8C & 5.94 & 0.0061 & DYNLT3 & 6.71 & 0.0338 \\
\hline SLC23A2 & 21.64 & 0.0114 & 92.30 & 0.0008 & KEAP1 & 5.66 & 0.0314 & GM4788 & 6.51 & 0.0118 \\
\hline SLC26A4 & 20.33 & 0.0004 & 8.83 & 0.0017 & PPFIBP2 & 5.63 & 0.0230 & CPNE1 & 6.50 & 0.0038 \\
\hline MATN4 & 19.45 & 0.0056 & 8.35 & 0.0044 & STUB1 & 5.61 & 0.0122 & SH3GL1 & 6.46 & 0.0027 \\
\hline EPB41L5 & 18.99 & 0.0004 & 11.32 & 0.0009 & NUMB & 5.46 & 0.0197 & PKP3 & 6.35 & 0.0094 \\
\hline ITGAV & 17.78 & 0.0000 & 23.53 & 0.0000 & EPB41L4B & 5.44 & 0.0176 & CYBB & 6.29 & 0.0250 \\
\hline KRT8 & 16.91 & 0.0001 & 9.81 & 0.0002 & APPL2 & 5.16 & 0.0287 & HADH & 6.29 & 0.0117 \\
\hline HP1BP3 & 15.64 & 0.0029 & 11.95 & 0.0061 & ANXA8 & 5.12 & 0.0250 & COPS6 & 6.14 & 0.0085 \\
\hline ITGA3 & 14.91 & 0.0001 & 17.14 & 0.0001 & SEPTIN_9 & 5.02 & 0.0114 & CAV2 & 6.11 & 0.0065 \\
\hline ABHD4 & 14.24 & 0.0004 & 13.06 & 0.0002 & USP4 & 4.99 & 0.0121 & PAPSS2 & 6.09 & 0.0324 \\
\hline COL6A2 & 13.71 & 0.0086 & 22.75 & 0.0029 & CGN & 4.92 & 0.0045 & ARFGEF1 & 5.96 & 0.0090 \\
\hline CPNE8 & 13.68 & 0.0042 & 40.43 & 0.0006 & STEAP4 & 4.79 & 0.0147 & MLLT4 & 5.95 & 0.0079 \\
\hline DDX5 & 13.59 & 0.0025 & 9.18 & 0.0036 & PRMT1 & 4.64 & 0.0089 & EXOC8 & 5.92 & 0.0065 \\
\hline ITGA6 & 13.47 & 0.0021 & 11.89 & 0.0022 & GGA1 & 4.44 & 0.0118 & CAV1 & 5.81 & 0.0069 \\
\hline RETNLA & 13.22 & 0.0029 & 15.46 & 0.0017 & RBBP4 & 4.38 & 0.0397 & CARS & 5.75 & 0.0532 \\
\hline POSTN & 13.11 & 0.0080 & 21.36 & 0.0027 & HECTD1 & 4.31 & 0.0206 & SLC39A8 & 5.56 & 0.0085 \\
\hline CTPS1 & 13.08 & 0.0001 & 16.39 & 0.0001 & DNM3 & 4.22 & 0.0291 & MSLN & 5.55 & 0.0013 \\
\hline DHX9 & 13.04 & 0.0089 & 9.61 & 0.0120 & OSMR & 4.17 & 0.0533 & SORBS3 & 5.50 & 0.0197 \\
\hline LMNA & 12.51 & 0.0003 & 14.49 & 0.0002 & EXOC4 & 4.15 & 0.0134 & COL4A2 & 5.46 & 0.0140 \\
\hline NDNF & 12.00 & 0.0036 & 30.60 & 0.0020 & ARF5 & 4.15 & 0.0478 & Q8CEZ4 & 5.39 & 0.0205 \\
\hline MACF1 & 11.87 & 0.0047 & 38.90 & 0.0005 & BRCC3 & 4.12 & 0.0279 & XPNPEP1 & 5.20 & 0.0291 \\
\hline S100A16 & 11.60 & 0.0025 & 7.81 & 0.0042 & SUGT1 & 3.99 & 0.0280 & SNX4 & 5.17 & 0.0176 \\
\hline CAPN7 & 10.88 & 0.0036 & 10.04 & 0.0030 & DNAJB4 & 3.85 & 0.0530 & RAB11FIP1 & 5.14 & 0.0095 \\
\hline MUC5AC & 9.84 & 0.0156 & 17.73 & 0.0046 & RASGRF2 & 3.84 & 0.0208 & COPS8 & 5.08 & 0.0200 \\
\hline FN1 & 9.58 & 0.0004 & 11.42 & 0.0002 & HERC4 & 3.81 & 0.0145 & VPS29 & 5.06 & 0.0441 \\
\hline CHMP3 & 8.72 & 0.0036 & 11.83 & 0.0014 & RTKN & 3.78 & 0.0429 & CLIP1 & 4.94 & 0.0142 \\
\hline PLXNA1 & 7.22 & 0.0010 & 20.10 & 0.0001 & ATG7 & 3.74 & 0.0419 & AGO2 & 4.80 & 0.0224 \\
\hline COL6A3 & 7.04 & 0.0025 & 15.77 & 0.0003 & ANKRD13A & 3.64 & 0.0510 & EIF3E & 4.60 & 0.0114 \\
\hline PTPRE & 6.92 & 0.0211 & 26.01 & 0.0017 & KLC2 & 3.63 & 0.0427 & GIPC1 & 4.53 & 0.0056 \\
\hline BIRC6 & 6.53 & 0.0263 & 44.62 & 0.0008 & NEK9 & 3.56 & 0.0540 & MON2 & 4.47 & 0.0062 \\
\hline ZDHHC5 & 5.96 & 0.0139 & 35.61 & 0.0009 & LPP & 3.48 & 0.0197 & CRYAB & 4.42 & 0.0026 \\
\hline
\end{tabular}


1032 Table 4: Top 50 protein signatures that had significantly reduced abundance in ozone1033 exposed mice versus air-exposed mice.

\begin{tabular}{|c|c|c|c|c|c|c|c|c|c|c|}
\hline \multicolumn{5}{|c|}{ Common in Both Genders } & \multicolumn{3}{|c|}{ Unique to Males } & \multicolumn{3}{|c|}{ Unique to Females } \\
\hline Protein & FC (Male) & adj.P.Val (Males) & FC (Females) & adj.P.Val (Females) & Protein & FC & adj.P.Val & Protein & FC & adj.P.Val \\
\hline MLF1 & -109.96 & 0.0047 & -1407.91 & 0.0018 & FABP1 & -34.74 & 0.0045 & E030010N08RIK & -41.09 & 0.0315 \\
\hline GDPD1 & -29.31 & 0.0049 & -9.27 & 0.0250 & SLC22A18 & -24.44 & 0.0259 & ATP13A1 & -27.45 & 0.0113 \\
\hline PMPCA & -27.02 & 0.0014 & -31.38 & 0.0025 & MAGT1 & -19.03 & 0.0169 & ARHGEF7 & -22.66 & 0.0071 \\
\hline SLC27A2 & -22.15 & 0.0029 & -33.84 & 0.0011 & UFL1 & -16.41 & 0.0186 & RNF213 & -21.56 & 0.0063 \\
\hline MERTK & -20.86 & 0.0009 & -6.88 & 0.0031 & AFP & -15.18 & 0.0329 & DAD1 & -19.74 & 0.0090 \\
\hline EFHC1 & -19.61 & 0.0037 & -6.09 & 0.0261 & EMD & \begin{tabular}{|l|}
-14.99 \\
\end{tabular} & 0.0343 & MIA3 & -18.24 & 0.0161 \\
\hline CLCC1 & -18.19 & 0.0114 & -15.72 & 0.0112 & DNAH9 & -13.86 & 0.0426 & GPAA1 & -17.64 & 0.0250 \\
\hline CYP4A12 & -16.69 & 0.0004 & -23.68 & 0.0002 & IGHV1-47 & -13.82 & 0.0419 & SLC27A1 & -15.49 & 0.0054 \\
\hline FGFR2 & -15.19 & 0.0014 & -49.82 & 0.0001 & FKBP8 & -13.19 & 0.0113 & ITPR3 & -15.14 & 0.0129 \\
\hline GM2A & -14.42 & 0.0018 & -24.17 & 0.0005 & FAM3C & -12.90 & 0.0085 & LMF1 & -13.03 & 0.0107 \\
\hline MTDH & -14.01 & 0.0043 & -11.51 & 0.0051 & CES2 & -12.05 & 0.0286 & KDELC2 & -12.61 & 0.0142 \\
\hline CYP4F & -13.44 & 0.0070 & -17.41 & 0.0035 & RILPL1 & -11.17 & 0.003 & THEM6 & -12.54 & 0.0105 \\
\hline LSP1 & -13.42 & 0.0001 & -9.36 & 0.0001 & IGKV9-124 & -9.75 & 0.0236 & EMC4 & -11.74 & 0.0461 \\
\hline IYD & -12.55 & 0.0061 & -9.62 & 0.0085 & HM13 & -9.05 & 0.0431 & NBAS & -11.52 & 0.0093 \\
\hline BNIP1 & -12.28 & 0.0037 & -12.61 & 0.0017 & SPCS3 & -9.04 & 0.0263 & BICD2 & -11.34 & 0.0170 \\
\hline MLF2 & -12.01 & 0.0206 & -11.17 & 0.0083 & PCCB & -8.82 & 0.0045 & SPAG6 & -10.84 & 0.0130 \\
\hline TRP53I11 & -11.40 & 0.0148 & -11.64 & 0.0183 & ALG2 & -7.90 & 0.0432 & LCLAT1 & -10.56 & 0.0144 \\
\hline CRELD2 & -11.30 & 0.0165 & -11.72 & 0.0081 & PCCA & -7.87 & 0.0053 & CNPY2 & -10.35 & 0.0075 \\
\hline ILVBL & -10.50 & 0.0357 & -8.61 & 0.0465 & CELA1 & -7.78 & 0.0539 & GNN & -10.27 & 0.0036 \\
\hline BC017158 & -10.19 & 0.0147 & -12.11 & 0.0088 & AK8 & -7.50 & 0.0543 & SLC5A8 & -10.26 & 0.0117 \\
\hline CES1F & -9.69 & 0.0113 & -20.50 & 0.0026 & AMY2 & -7.14 & 0.0348 & TNPO1 & -10.19 & 0.0020 \\
\hline ATP2A3 & -9.18 & 0.0304 & -16.25 & 0.0107 & DHRS7B & -7.06 & 0.0188 & POFUT1 & -9.844 & 0.0022 \\
\hline THBS3 & -9.11 & 0.0147 & -8.92 & 0.0196 & VAMP5 & -6.65 & 0.0106 & TMC4 & -9.738 & 0.0027 \\
\hline GAS6 & -9.04 & 0.0008 & -16.02 & 0.0002 & IGK-V19-17 & -6.56 & 0.0132 & CNTFR & -9.637 & 0.0029 \\
\hline FMO1 & -8.95 & 0.0157 & -9.74 & 0.0107 & FAM213A & -6.24 & 0.0429 & MCFD2 & -9.555 & 0.0051 \\
\hline TMX2 & -8.79 & 0.0440 & -7.70 & 0.0519 & TMED4 & -6.17 & 0.0246 & RSPH4A & -9.498 & 0.0141 \\
\hline PIGS & -8.78 & 0.0261 & -7.32 & 0.0318 & IDH3B & -6.00 & 0.0281 & KDSR & -9.468 & 0.0137 \\
\hline PGRMC1 & -8.17 & 0.0021 & -8.46 & 0.0014 & TMCO1 & -5.96 & 0.0323 & SIGMAR1 & -9.407 & 0.0061 \\
\hline DPM1 & -8.08 & 0.0141 & -11.59 & 0.0057 & SFXN3 & -5.91 & 0.0122 & ADPGK & -9.22 & 0.0197 \\
\hline CDIPT & -7.93 & 0.0515 & -11.64 & 0.0390 & ECI1 & -5.79 & 0.0114 & GYS1 & -9.11 & 0.0142 \\
\hline LYZ2 & -7.53 & 0.0007 & -11.08 & 0.0002 & FAM160B1 & -5.77 & 0.0045 & SUCLG2 & -8.97 & 0.0279 \\
\hline CHID1 & -7.42 & 0.0147 & -17.98 & 0.0039 & SGSH & -5.77 & 0.0114 & IGKV10-94 & -8.701 & 0.0111 \\
\hline TMEM205 & -7.21 & 0.0088 & -8.57 & 0.0049 & ECHS1 & -5.72 & 0.008 & ABHD16A & -8.674 & 0.0183 \\
\hline HACD2 & -7.02 & 0.0194 & -8.42 & 0.0107 & BC017643 & -5.63 & 0.0237 & DHCR7 & -8.575 & 0.0146 \\
\hline METTL7A1 & -6.87 & 0.0053 & -8.58 & 0.0027 & ICA1L & -5.50 & 0.0058 & EPB4 & -8.257 & 0.0036 \\
\hline SLC27A4 & -6.79 & 0.0292 & -13.97 & 0.0069 & UBE2G2 & -5.48 & 0.03 & FKBP2 & -7.817 & 0.0137 \\
\hline WFDC2 & -6.74 & 0.0063 & -13.51 & 0.0011 & GTPBP4 & -5.13 & 0.04 & BPIFB5 & -7.806 & 0.0051 \\
\hline STT3B & -6.50 & 0.0405 & -10.01 & 0.0158 & VKORC1 & -4.90 & 0.0527 & IGHV1-5 & -7.723 & 0.0183 \\
\hline CES1E & -6.45 & 0.0221 & -15.26 & 0.0035 & LRRC37A & -4.84 & 0.0082 & LMF2 & -7.62 & 0.0253 \\
\hline FGFR3;FGFR & -6.44 & 0.0014 & -11.70 & 0.0002 & PCDHGC3 & -4.72 & 0.0426 & PRSS1 & -7.527 & 0.0322 \\
\hline UGT1A6 & -6.38 & 0.0199 & -9.30 & 0.0077 & IGHV1-9 & -4.66 & 0.0268 & SDF2L1 & -7.512 & 0.0247 \\
\hline SPCS1 & -6.34 & 0.0236 & -15.49 & 0.0035 & ERGIC1 & -4.61 & 0.0508 & TLR5 & -7.421 & 0.0090 \\
\hline ITPR1 & -6.28 & 0.0530 & -15.03 & 0.0170 & HADHA & -4.55 & 0.0303 & ACADM & -7.384 & 0.0283 \\
\hline TMEM35 & -6.10 & 0.0121 & -17.46 & 0.0027 & FCN1 & -4.36 & 0.0413 & PRKAR2B & -7.375 & 0.0004 \\
\hline TBL2 & -5.75 & 0.0422 & -10.60 & 0.0113 & DDAH2 & -4.26 & 0.0427 & RPS25 & -7.204 & 0.0102 \\
\hline CYP2A & -5.64 & 0.0014 & -12.45 & 0.0001 & ORM1 & -4.19 & 0.0076 & KTN1 & -7.091 & 0.0241 \\
\hline SLC4A1 & -5.37 & 0.0527 & -39.16 & 0.0025 & PTRH2 & -4.14 & 0.029 & IFITM1 & -7.08 & 0.0033 \\
\hline LYZ1 & -4.78 & 0.0012 & -13.95 & 0.0000 & CREG1 & -4.09 & 0.0059 & TAPBP & -7.005 & 0.0141 \\
\hline ALG11 & -4.57 & 0.0527 & -15.11 & 0.0097 & SIRPA & -3.99 & 0.0198 & SELT & -6.912 & 0.0462 \\
\hline CFAP20 & -3.59 & 0.0230 & -21.17 & 0.0005 & HDHD2 & -3.98 & 0.0292 & LMAN2L & -6.771 & 0.0102 \\
\hline
\end{tabular}


1039 Table 5: Comparative analyses of enriched protein signatures from ozone-exposed mice 1040 and transcriptome from three lung compartments.

1041

1042

\begin{tabular}{|c|c|c|}
\hline $\begin{array}{l}\text { Gene Signatures upregulated } \\
\text { in Airways, Parenchyma or } \\
\text { Alveolar Macrophages } \\
\text { (FC>1; adj p-value }<0.05 \text { ) }\end{array}$ & $\begin{array}{c}\text { Number of Enriched exosomal } \\
\text { proteins (ozone vs air) (FC }>2 ; \\
\text { adj p-value }<0.05 \text { ) }\end{array}$ & Selected Protein Signatures \\
\hline $\begin{array}{l}\text { Airways, Parenchyma, and } \\
\text { Alveolar Macrophages }\end{array}$ & 180 & $\begin{array}{l}\text { EPHA2, ITGA3, RETNLA, SLC26A4, MUC5AC, S100A16, SFTPC, F3, ITGB4, } \\
\text { TSPAN8, FBL, ADAM10, AGER, CLCA1, S100A14, TGM2, CLEC7A, FGG, } \\
\text { MUC4, TFRC, TSPO, LRP2, ANXA4, ANXA1, CLDN18, ADAM9, LDLR }\end{array}$ \\
\hline Airways & 47 & ITGA6, ITGB1, ATP2B1, CKAP5, HGS, DNAJB4, \\
\hline Parenchyma & 38 & CD151, ABCA3, ATP9A, FGA, APOC1, TLR2, TGFBR2, HIST1H1E \\
\hline Alveolar macrophages & 59 & $\begin{array}{l}\text { S100A9, TIMP3, PLA2G7, CD81, ANXA11, MACF1, TMEM2, H2-AB1, CAV1, } \\
\text { PTGFRN, BMPR1A }\end{array}$ \\
\hline Airways and Parenchyma & 66 & $\begin{array}{l}\text { LMNA, H1F0, SAA1, TGM1, LGALS3, LGL2, HIST1H3B, APOD, LTF, A2M, } \\
\text { IL1RN, S100A10, S100A11, EPCAM, SLC44A2 }\end{array}$ \\
\hline $\begin{array}{l}\text { Airways and Alveolar } \\
\text { macrophages }\end{array}$ & 44 & $\begin{array}{l}\text { TOP1, TSPAN2, TSPAN15, TNC, FCGR2B, CEACAM1, TOLLIP, CPNE8, ECM1, } \\
\text { FLNB, CAPN7 }\end{array}$ \\
\hline $\begin{array}{l}\text { Parenchyma and Alveolar } \\
\text { macrophages }\end{array}$ & 63 & $\begin{array}{l}\text { ITGAV, COL6A1-3, TNC, SLC23A2, ITGF3, ITGA9, MMP3, COL4A2, KEAP1, } \\
\text { C1QC, COL12A1, SLC16A1 }\end{array}$ \\
\hline None & 71 & POSTN, NGP, HIST1G2BR, ARHGEF2, CLDN1, AGO2, ANXA6, FGB \\
\hline
\end{tabular}

1043

1044

1045

1046

1047

1048

1049

1050

1051

1052

1053

1054

1055

1056

1057

1058

1059

1060

1061 
1063 Fig. 1: (A) Ozone exposure causes exaggerated lung injury and inflammatory mediators in 1064 ozone-exposed mice. (A) Protein concentration $(\mu \mathrm{g} / \mathrm{ml})$ in the cell-free BALF from the air- and 1065 ozone -exposed males and females. Concentration (pg/ml) of G-CSF (B), MIP-1 $\beta$ (C), CXCL1 1066 (KC) (D), IP-10 (E), IL-6 (F), IL5 (G) in the cell-free BALF from air- and ozone-exposed males 1067 and females. (H) Double-stranded DNA (dsDNA) concentration (ng/ml) in the cell-free BALF 1068 from the air- and ozone-exposed males and females. Error bars represent SEM. ${ }^{*} p<0.05,{ }^{* *} p<0.01$, $* * * p<0.001, * * * * p<0.0001$ using one-way ANOVA followed by Tukey's multiple comparison 1070 post hoc test. ( $\mathrm{n}=13-14$ per group). BALF, bronchoalveolar lavage fluid; G-CSF, Granulocyte colony-stimulating factor; MIP-1 $\beta$, Macrophage Inflammatory Protein -1 $\beta$; CXCL1, Chemokine

1072 (C-X-C motif) ligand 1; (KC, Keratinocytes-derived chemokine); IP-10, Interferon-gamma 1073 induced protein 10; IL-6, Interleukin 6; IL-5, Interleukin 5.

Fig. 2: Exosome harvest and analyses for exosome-specific protein signatures. (A) Flow 1076 diagram delineating designated steps involved in BALF processing for proteomics data analyses. (B) Total protein yield $(\mu \mathrm{g})$ in the exosomes harvested from the air- and ozone-exposed males and females. Error bars represent SEM**** $p<0.0001$ using one-way ANOVA followed by Tukey's multiple comparison post hoc test. ( $n=3$ per group). (C) Venn diagram to show that 822 out of 1225 exosome-specific markers obtained from Vesiclepedia database were present in exosomes harvested in this study. (D) Table showing 29 exosome markers that were represented in the top $1082 \quad 20 \%$ of the most abundant proteins.

1083

1084 Fig. 3: Ozone exposure results in alterations in the airspace exosome-bound proteome. (A) 1085 Two-dimensional principal component (PC) analysis plot using PC1 and PC2 on differentially 1086 enriched proteins (after normalization) in exosomes from the air- and ozone-exposed mice. (B-F) 1087 Volcano plots depicting differentially abundant proteins (enriched and low-abundance) in four 1088 different comparisons that were identified using cutoff criteria [Log2 Fold change $>2,-\log 10$ 1089 (FDR adjusted $p$-values $<0.05)$ ]. (B) air-exposed females versus air-exposed males, (C) ozone1090 exposed females versus ozone-exposed males, (D) ozone-exposed males versus air-exposed males, 1091 (E) ozone-exposed females versus air-exposed females. ( $\mathrm{n}=3$ per sex per treatment) and (F) ozone1092 exposed mice (both sexes) versus air-exposed mice (both sexes). Venn diagram (G) depicting 
1093 common and unique differentially enriched proteins (enriched and low-abundance) in ozone1094 exposed males versus air-exposed males and ozone-exposed females versus air-exposed females. 1095 Tabular (H) summary of the Venn diagram (G).

1096 Fig. 4: Heat map (A) for normalized protein abundance values (Z-scores) representing macrophage 1097 activation to classical (CAM, classically activated macrophages) or alternative (AAM, 1098 alternatively activated macrophages) responses. Higher and lower expressions of each protein are 1099 represented by red and blue colors, respectively. (B-G) Immunohistochemical analyses of lung 1100 sections for cell-specific expression of AAM-associated protein i.e. RETNLA (FIZZ1). Red 1101 arrows point to the RETNLA-stained epithelial cells (B, air-exposed; C, ozone-exposed). Green 1102 arrows points to the macrophages that were positively stained for RETNLA (C, ozone-exposed). 1103 (D) Bar graph showing the proportion of epithelial cells in the small airways that were stained 1104 positive for RETNLA. Error bars represent SEM****p<0.0001 using one-way ANOVA followed 1105 by Tukey's multiple comparison post hoc test. (n=3-5 per group). Green arrows points to the 1106 macrophages that remained unstained (E, air-exposed; G, ozone-exposed;) or those that were 1107 intensely stained for RETNLA (F, ozone-exposed).

1109 Fig. 5: (A) Heat maps for normalized values (Z-scores) for proteins associated with 1110 mucoinflammatory lung diseases in mice and humans. Low-resolution heat map (Left) depicting 1111 expression patterns for the entire muco-inflammatory proteins (High resolution heatmap with 1112 protein names is presented as Supplemental Figure 1). Heat map corresponding to protein 1113 signatures that were low-abundance (Top) or enriched (Bottom) in exosomes from ozone-exposed 1114 mice was amplified for better resolution. (B-G) Immunohistochemical analyses of lung sections 1115 for expression of MUC5B in large airways (B and C) and small airways ( $\mathbf{E}$ and $\mathbf{F}$ ) from air1116 exposed (B and E) and ozone-exposed (C and F) mice. Red arrows point to the MUC5B-stained 1117 epithelial cells (B, air-exposed; C and F, ozone-exposed). Red arrows points to the epithelial that 1118 were positively stained for MUC5B. Bar graph showing the proportion of epithelial cells in the 1119 large (D) and small (G) airways that were stained positive for MUC5B. Error bars represent SEM $1120 * p<0.05, \mathrm{SEM}^{* * * *} p<0.0001$ using one-way ANOVA followed by Tukey's multiple comparison 1121 post hoc test. ( $\mathrm{n}=5$ per group).

1123 Fig. 6: Biological pathway analyses on abundant proteins in BALF exosomes from air- and 
1124 ozone-exposed mice. (A) Ingenuity pathway analysis (IPA) on most abundant (top 10\%; 326 out 1125 of 3258 identified proteins, determined by Log2 VSN normalized iBAQ MS1 intensities) proteins 1126 in exosomes harvested from air-exposed mice. Pathways related to "molecular and cellular

1127 functions" and "Physiological system development and function" categories were interrogated for 1128 their enrichment. (B) Ingenuity pathway analysis (IPA) on most abundant (top 10\%; 342 out of 11293421 identified proteins, determined by Log2 VSN normalized iBAQ MS1 intensities) proteins in 1130 exosomes harvested from ozone-exposed mice. The asterisk represents pathways that were 1131 uniquely enriched in exosomes harvested from ozone-exposed mice.

1133 Fig. 7: Comparative analysis of proteins in BALF exosomes from ozone- vs air-exposed mice 1134 reveals enrichment of inflammation/injury associated pathways.

11351255 differentially enriched proteins (Total,1255; enriched, 568; low-abundance, 687) were 1136 subjected to Ingenuity pathway analysis (IPA). Ingenuity pathway analysis (IPA) for the 1137 enrichment of (A) disease/functional pathways and (B) canonical pathways/biological networks 1138 altered in the exosomes from ozone-exposed mice. (C) IPA was performed compare differentially 1139 expressed signatures in ozone-exposed males (versus air-exposed males; 380, enriched; 438, low1140 abundance) and ozone-exposed females (versus air-exposed females; 427, enriched; 474, low1141 abundance). Z-scores were used to plot heat maps. Only selected pathways are presented in this 1142 figure. A detailed heat map with all the differentially enriched pathways is included in

\section{Supplemental Fig. 2.}




\section{Supplemental Figures:}

Supplemental Fig. 1: High-resolution heatmap (supporting image for Figure 5A) for normalized

1158 expression values (Z-scores) of protein signatures associated with mucoinflammatory lung 1159 diseases in mice and humans.

1161 Supplemental Fig. 2: IPA was performed compare differentially expressed signatures in ozone1162 exposed males (versus air-exposed males; 380, enriched; 438, low-abundance) and ozone-exposed 1163 females (versus air-exposed females; 427, enriched; 474, low-abundance). Z-scores were used to 1164 plot heat maps.

1166 Supplemental Fig. 3: STRING database protein-protein interaction network analyses on enriched 1167 proteins (568) in exosomes from ozone-exposed mice versus air-exposed mice. Interactions were 1168 determined based on evidence, using the highest confidence level (0.9) setting. 547 nodes and 11691052 edges were identified. Disconnected nodes were selected to be hidden. (PPI enrichment p1170 value $<1.0 \times 10^{-16}$ ). Proteins involved in ECM-receptor interaction (Counts=14/81; FDR adjusted $1171 \mathrm{p}$-value $<2.79 \times 10^{-06}$ ), Tight Junction (Counts=18/165; FDR adjusted p-value $<1.32 \times 10^{-5}$ ), 1172 Membrane trafficking (Counts=47/523; FDR adjusted p-value $<5.5 \mathrm{X}^{-11} 0^{-11}$ ), Extracellular matrix 1173 organization (Counts $=31 / 246$; FDR adjusted $p$-value $<2.53 \times 10^{-10}$ ), Cell junction organization 1174 (Counts=16/63; FDR adjusted p-value $<5.07 \times 10^{-09}$ ), Neutrophil degranulation (Counts=39/476; 1175 FDR adjusted $\mathrm{p}$-value $<2.62 \times 10^{-08}$ ), Apoptosis (Counts=13/93; FDR adjusted $\mathrm{p}$-value $<6.28 \times 10^{-}$ $1176{ }^{05}$ ), and Adaptive immune system (Counts=34/652; FDR adjusted $p$-value $<0.0014$ ) were encircled. 
Figures
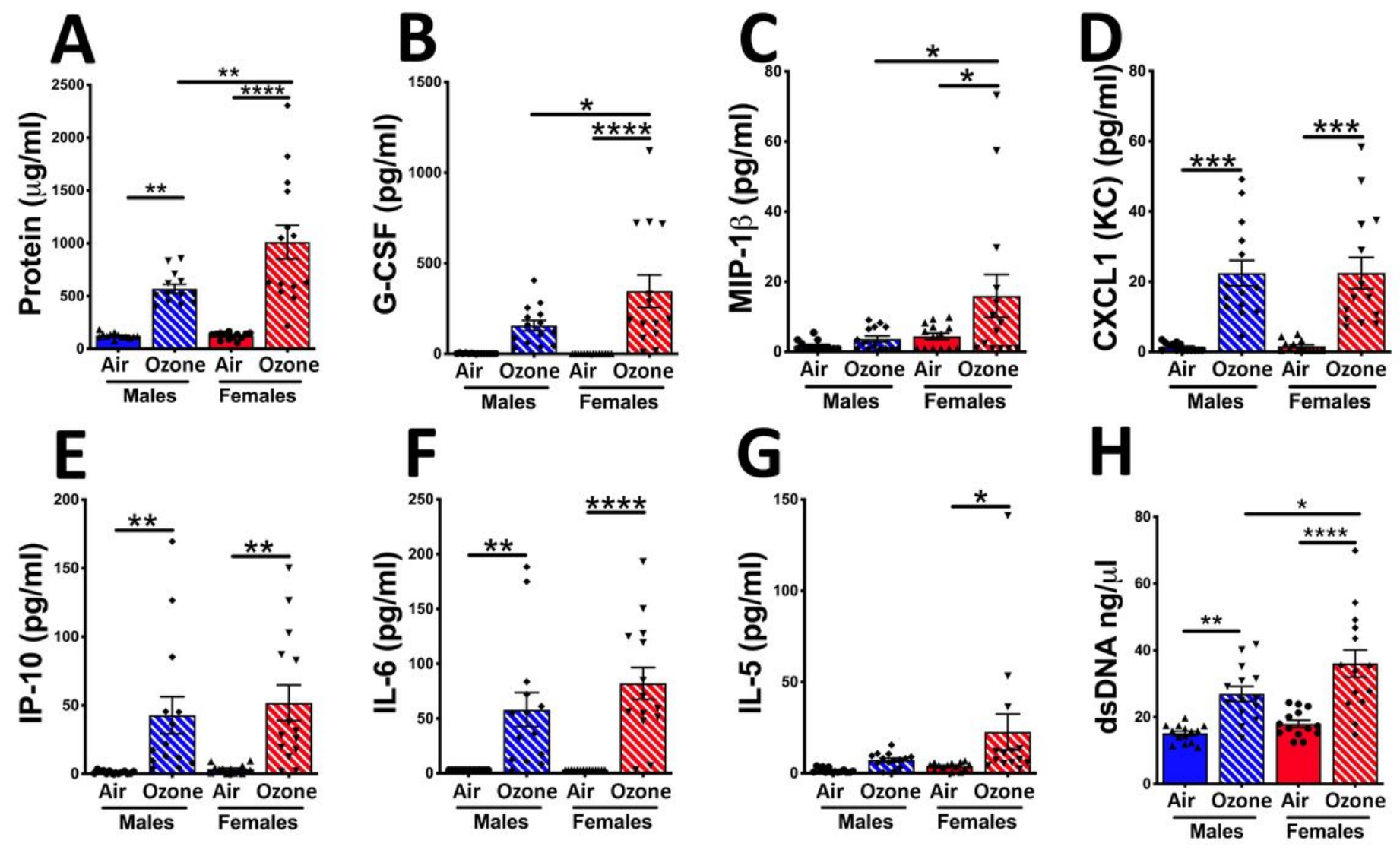

Figure 1

Figure 1

(A) Ozone exposure causes exaggerated lung injury and inflammatory mediators in ozone-exposed mice. (A) Protein concentration $(\mu \mathrm{g} / \mathrm{ml})$ in the cell-free BALF from the air- and ozone -exposed males and females. Concentration (pg/ml) of G-CSF (B), MIP-1b (C), CXCL1 (KC) (D), IP-10 (E), IL-6 (F), IL5 (G) in the cell-free BALF from air- and ozone-exposed males and females. $(\mathrm{H})$ Double-stranded DNA (dsDNA) concentration $(\mathrm{ng} / \mathrm{ml})$ in the cell-free BALF from the air- and ozone-exposed males and females. Error bars represent SEM. ${ }^{*} p<0.05,{ }^{* *} p<0.01,{ }^{* \star *} p<0.001,{ }^{* \star * *} p<0.0001$ using one-way ANOVA followed by Tukey's multiple comparison post hoc test. ( $n=13-14$ per group). BALF, bronchoalveolar lavage fluid; $G$ CSF, Granulocyte colony-stimulating factor; MIP-1b, Macrophage Inflammatory Protein -1b; CXCL1, Chemokine (C-X-C motif) ligand 1; (KC, Keratinocytes-derived chemokine); IP-10, Interferon-gamma induced protein 10; IL-6, Interleukin 6; IL-5, Interleukin 5. 
A

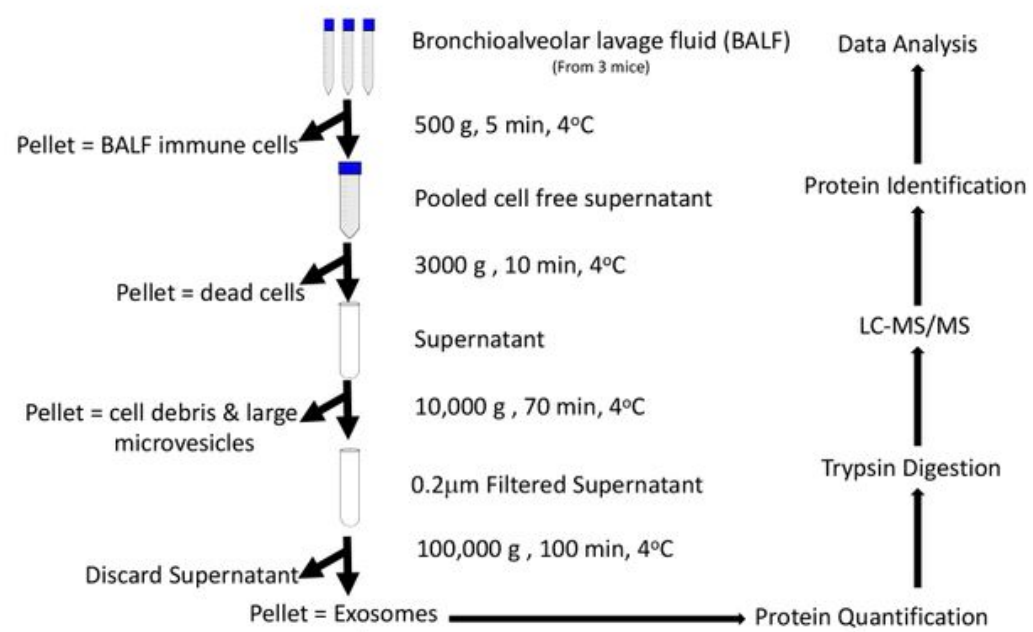

B
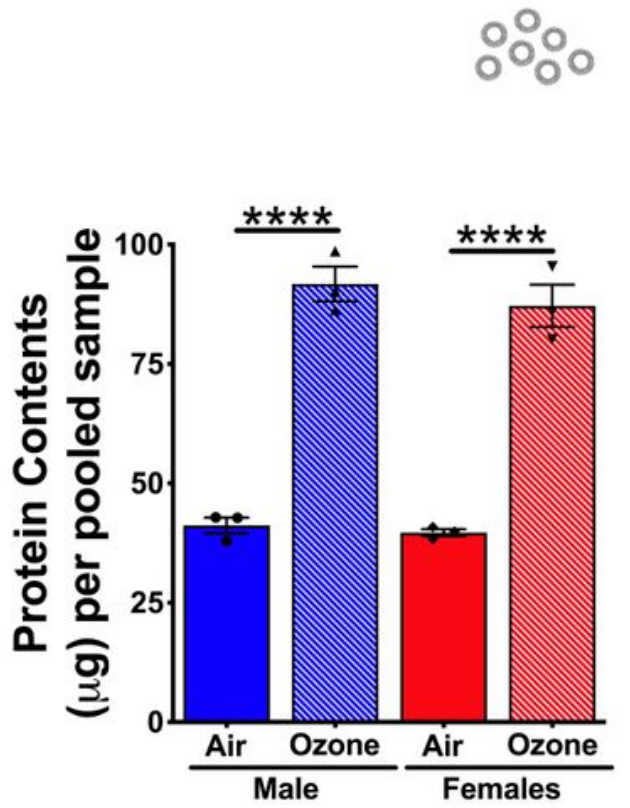

C

Vesiclepedia

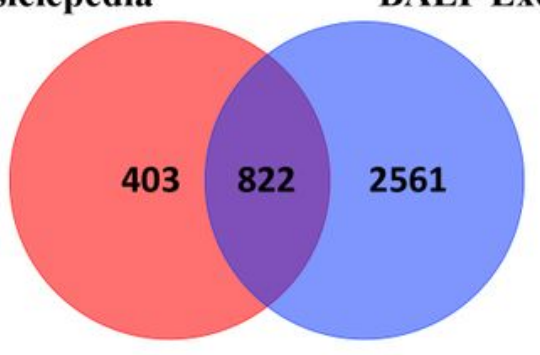

D

\begin{tabular}{|c|c|}
\hline Protein Description & Protein Name \\
\hline Annexin A5 & ANXA5 \\
\hline CD63 antigen & CD63 \\
\hline CD81 antigen & CD81 \\
\hline CD82 antigen & CD82 \\
\hline CD9 antigen & CD9 \\
\hline Epithelial cell adhesion molecule & EPCAM, CD326 \\
\hline Flotillin-1 & FLOT1 \\
\hline Heat shock $70 \mathrm{kDa}$ protein 1 & HSPAl \\
\hline Heat shock $70 \mathrm{kDa}$ protein 4 & HSPA4 \\
\hline Intercellular adhesion molecule 1 & ICAMI \\
\hline Lactadherin & MFGE8 \\
\hline Mucin-1 & MUCl \\
\hline Programmed cell death 6-interacting protein & PDCD6IP, ALIX \\
\hline Ras-related protein Rab-10 & RAB10 \\
\hline Ras-related protein Rab-11 & RAB11 \\
\hline Ras-related protein Rab-14 & RAB14 \\
\hline Ras-related protein Rab-18 & RAB18 \\
\hline Ras-related protein Rab-1A & RABl \\
\hline Ras-related protein Rab-1B & RAB1B \\
\hline Ras-related protein Rab-21 & RAB21 \\
\hline Ras-related protein $\mathrm{Rab}-27 \mathrm{~A}$ & RAB27A \\
\hline Ras-related protein Rab- 2 & RAB2 \\
\hline Ras-related protein Rab-35 & RAB35 \\
\hline Ras-related protein Rab-5C & RAB5C \\
\hline Ras-related protein Rab-6A & RAB6A \\
\hline Ras-related protein Rab-7a & RAB7A \\
\hline Ras-related protein Rab- $8 \mathrm{~A}$ & RAB8A \\
\hline Syntenin-1 & SDCBP \\
\hline Tumor susceptibility gene 101 protein & TSG101 \\
\hline
\end{tabular}

Figure 2

\section{Figure 2}

Exosome harvest and analyses for exosome-specific protein signatures. (A) Flow diagram delineating designated steps involved in BALF processing for proteomics data analyses. (B) Total protein yield $(\mu \mathrm{g})$ in the exosomes harvested from the air- and ozone-exposed males and females. Error bars represent SEM ${ }^{\star \star \star \star} p<0.0001$ using one-way ANOVA followed by Tukey's multiple comparison post hoc test. $(n=3$ per group). (C) Venn diagram to show that 822 out of 1225 exosome-specific markers obtained from 
Vesiclepedia database were present in exosomes harvested in this study. (D) Table showing 29 exosome markers that were represented in the top $20 \%$ of the most abundant proteins.
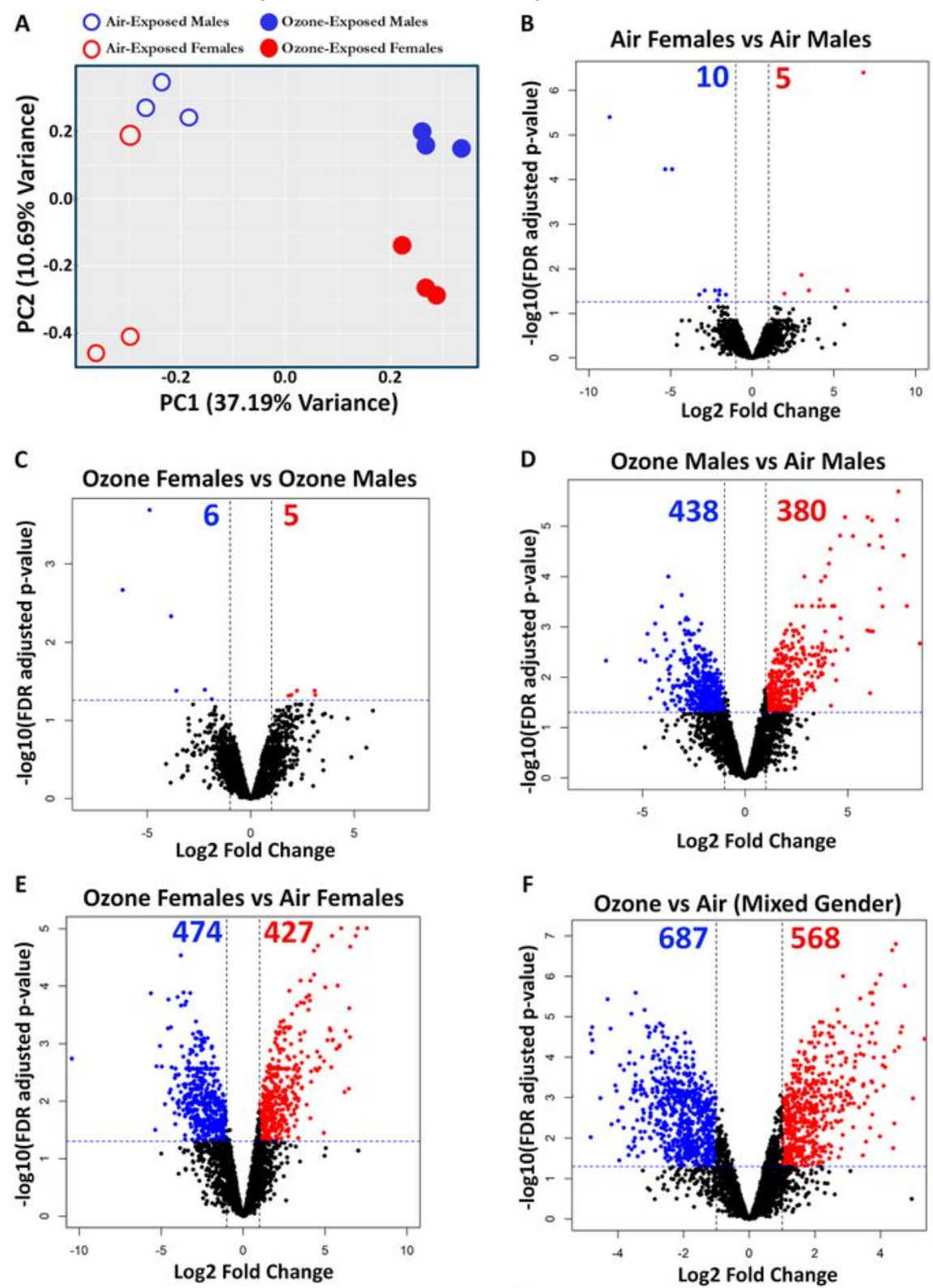

G

\section{Ozone vs Air}

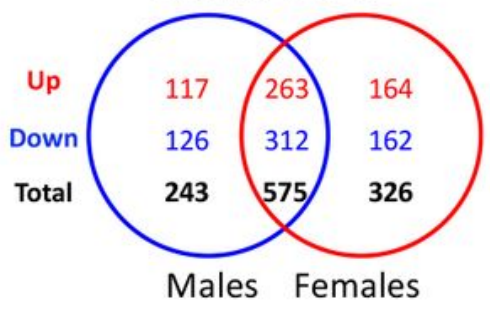

\begin{tabular}{|l|c|c|c|c|}
\hline & \multicolumn{2}{|c|}{$\begin{array}{c}\text { Males } \\
\text { (Ozone vs Air) }\end{array}$} & \multicolumn{2}{c|}{$\begin{array}{c}\text { Females } \\
\text { (Ozone vs Air) }\end{array}$} \\
\hline & Up & Down & Up & Down \\
\hline Unique & 117 & 126 & 164 & 162 \\
\hline Common & 263 & 312 & 263 & 312 \\
\hline Total & 380 & 438 & 427 & 474 \\
\hline
\end{tabular}

Figure 3

\section{Figure 3}

Ozone exposure results in alterations in the airspace exosome-bound proteome. (A) Two-dimensional principal component (PC) analysis plot using PC1 and PC2 on differentially enriched proteins (after normalization) in exosomes from the air- and ozone-exposed mice. (B-F) Volcano plots depicting 
differentially abundant proteins (enriched and low-abundance) in four different comparisons that were identified using cutoff criteria [Log2 Fold change>2, -Log10 (FDR adjusted p-values<0.05)]. (B) airexposed females versus air-exposed males, (C) ozone exposed females versus ozone-exposed males, (D) ozone-exposed males versus air-exposed males, $(E)$ ozone-exposed females versus air-exposed females. $(n=3$ per sex per treatment) and $(F)$ ozone exposed mice (both sexes) versus air-exposed mice (both sexes). Venn diagram (G) depicting common and unique differentially enriched proteins (enriched 1093 and low-abundance) in ozone exposed males versus air-exposed males and ozone-exposed females versus air-exposed females. Tabular $(H)$ summary of the Venn diagram $(G)$. 

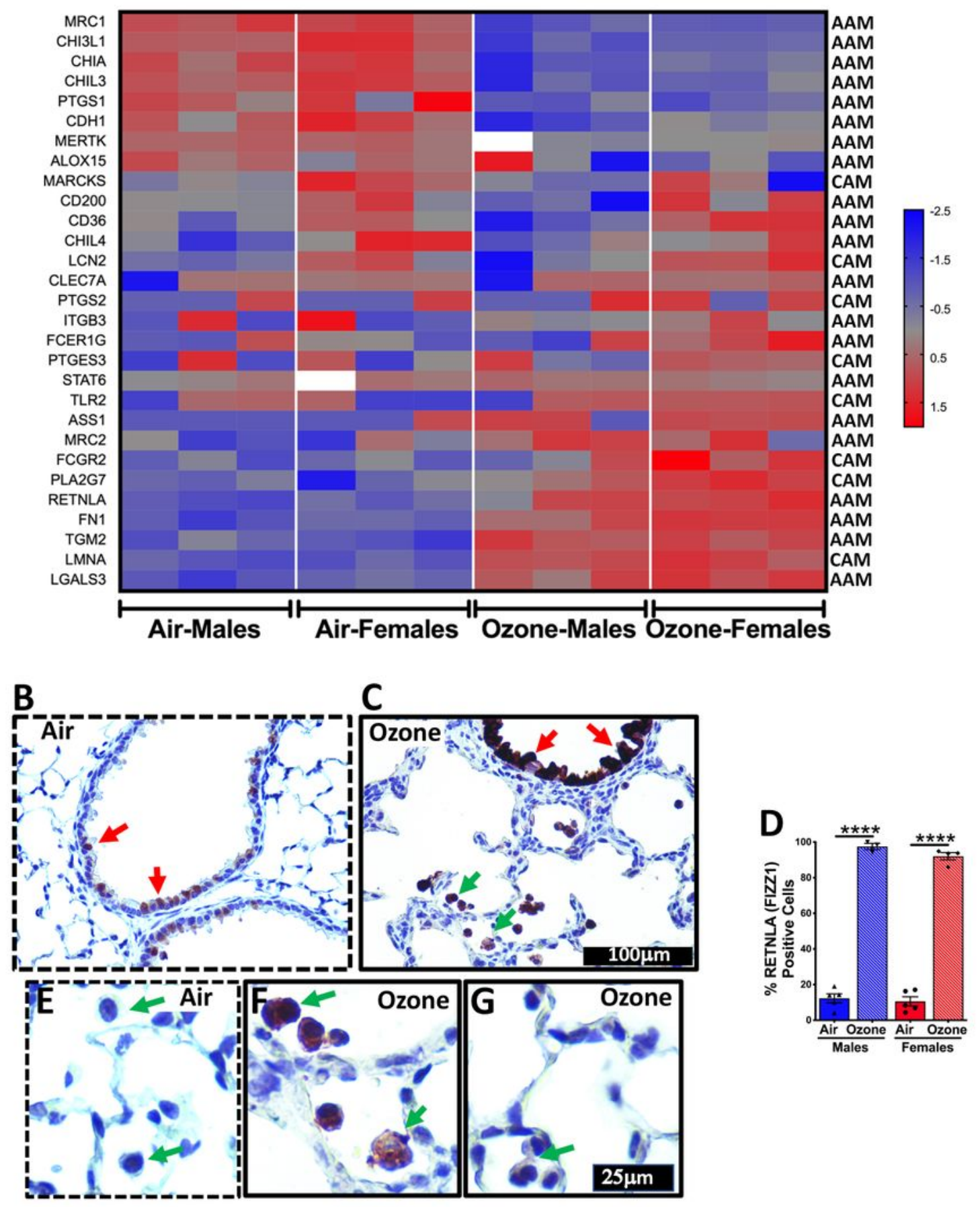

Figure 4

Figure 4

Heat map (A) for normalized protein abundance values (Z-scores) representing macrophage activation to classical (CAM, classically activated macrophages) or alternative (AAM, alternatively activated macrophages) responses. Higher and lower expressions of each protein are represented by red and blue colors, respectively. (B-G) Immunohistochemical analyses of lung sections for cell-specific expression of AAM-associated protein i.e. RETNLA (FIZZ1). Red arrows point to the RETNLA-stained epithelial cells (B, 
air-exposed; C, ozone-exposed). Green arrows points to the macrophages that were positively stained for RETNLA (C, ozone-exposed). (D) Bar graph showing the proportion of epithelial cells in the small airways that were stained positive for RETNLA. Error bars represent SEM****p $<0.0001$ using one-way ANOVA followed by Tukey's multiple comparison post hoc test. ( $n=3-5$ per group). Green arrows points to the macrophages that remained unstained (E, air-exposed; $G$, ozone-exposed;) or those that were intensely stained for RETNLA (F, ozone-exposed). Note: The designations employed and the presentation of the material on this map do not imply the expression of any opinion whatsoever on the part of Research Square concerning the legal status of any country, territory, city or area or of its authorities, or concerning the delimitation of its frontiers or boundaries. This map has been provided by the authors. 

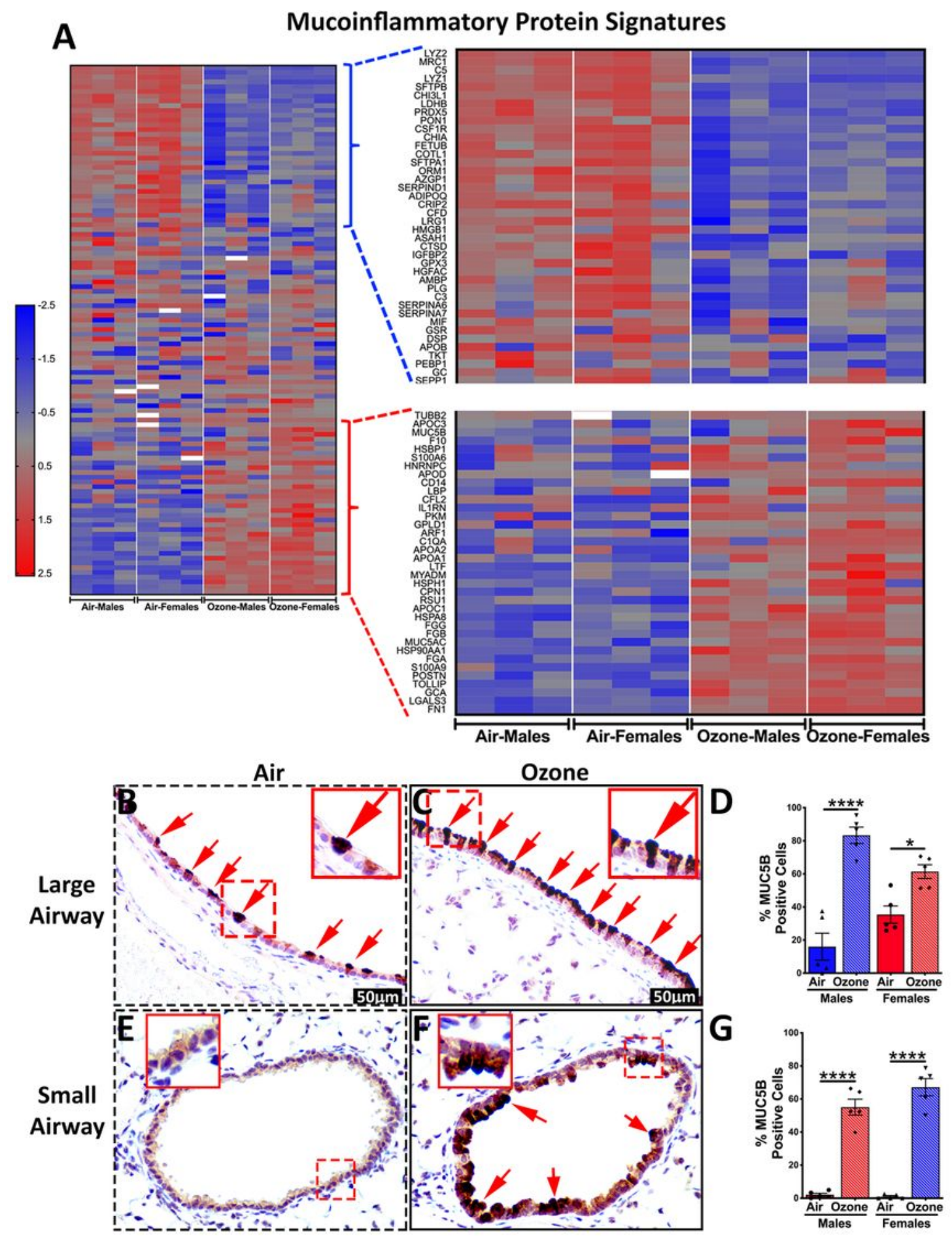

Figure 5

\section{Figure 5}

(A) Heat maps for normalized values (Z-scores) for proteins associated with mucoinflammatory lung diseases in mice and humans. Low-resolution heat map (Left) depicting expression patterns for the entire muco-inflammatory proteins (High resolution heatmap with protein names is presented as Supplemental Figure 1). Heat map corresponding to protein signatures that were low-abundance (Top) or enriched (Bottom) in exosomes from ozone-exposed mice was amplified for better resolution. (B-G) 
Immunohistochemical analyses of lung sections for expression of MUC5B in large airways (B and C) and small airways ( $E$ and $F$ ) from air exposed $(B$ and $E$ ) and ozone-exposed ( $C$ and $F$ ) mice. Red arrows point to the MUC5B-stained epithelial cells (B, air-exposed; $C$ and F, ozone-exposed). Red arrows points to the epithelial that were positively stained for MUC5B. Bar graph showing the proportion of epithelial cells in the large (D) and small (G) airways that were stained positive for MUC5B. Error bars represent SEM ${ }^{*} p<0.05$, SEM ${ }^{\star \star \star \star} p<0.0001$ using one-way ANOVA followed by Tukey's multiple comparison post hoc test. ( $n=5$ per group). Note: The designations employed and the presentation of the material on this map do not imply the expression of any opinion whatsoever on the part of Research Square concerning the legal status of any country, territory, city or area or of its authorities, or concerning the delimitation of its frontiers or boundaries. This map has been provided by the authors. 
A Top $10 \%$ most abundant proteins in air-exposed mice

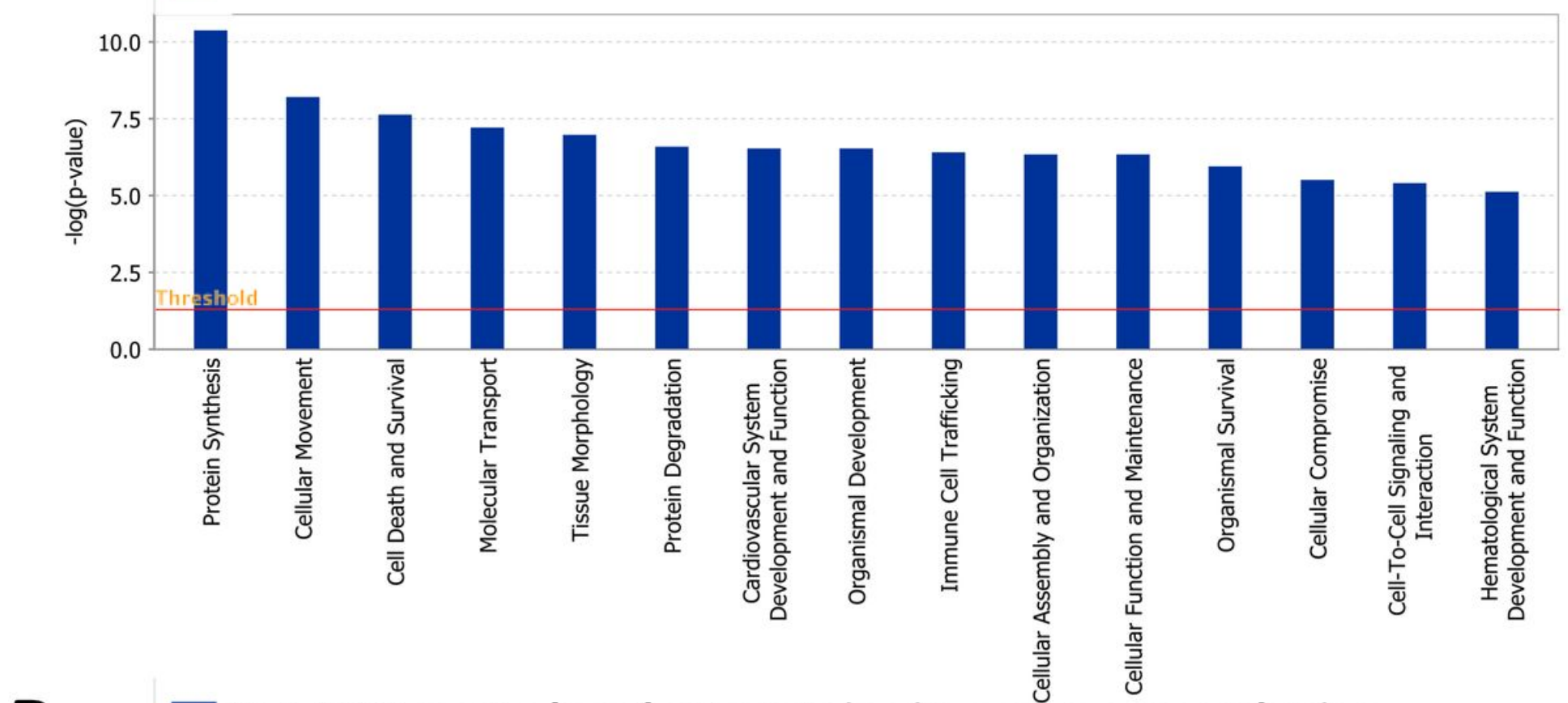

B Top $10 \%$ most abundant proteins in ozone-exposed mice

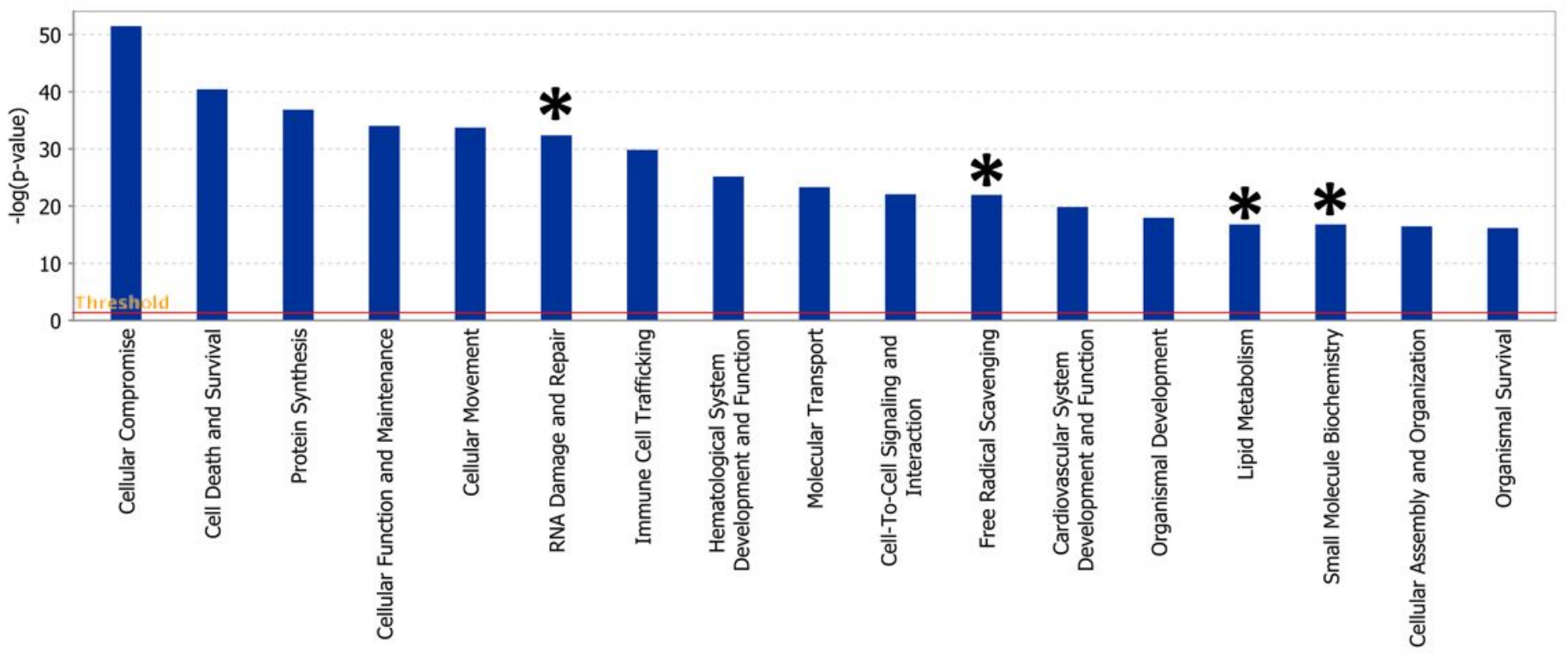

Figure 6

Figure 6

Biological pathway analyses on abundant proteins in BALF exosomes from air- and ozone-exposed mice. (A) Ingenuity pathway analysis (IPA) 1124 on most abundant (top 10\%; 326 out of 3258 identified proteins, determined by Log2 VSN normalized iBAQ MS1 intensities) proteins in exosomes harvested from air-exposed mice. Pathways related to "molecular and cellular functions" and "Physiological system development and function" categories were interrogated for their enrichment. (B) Ingenuity pathway analysis (IPA) on most abundant (top $10 \%$; 342 out of 3421 identified proteins, determined by Log2 VSN 

asterisk represents pathways that were uniquely enriched in exosomes harvested from ozone-exposed mice.

\section{A}

\section{Ozone vs Air}

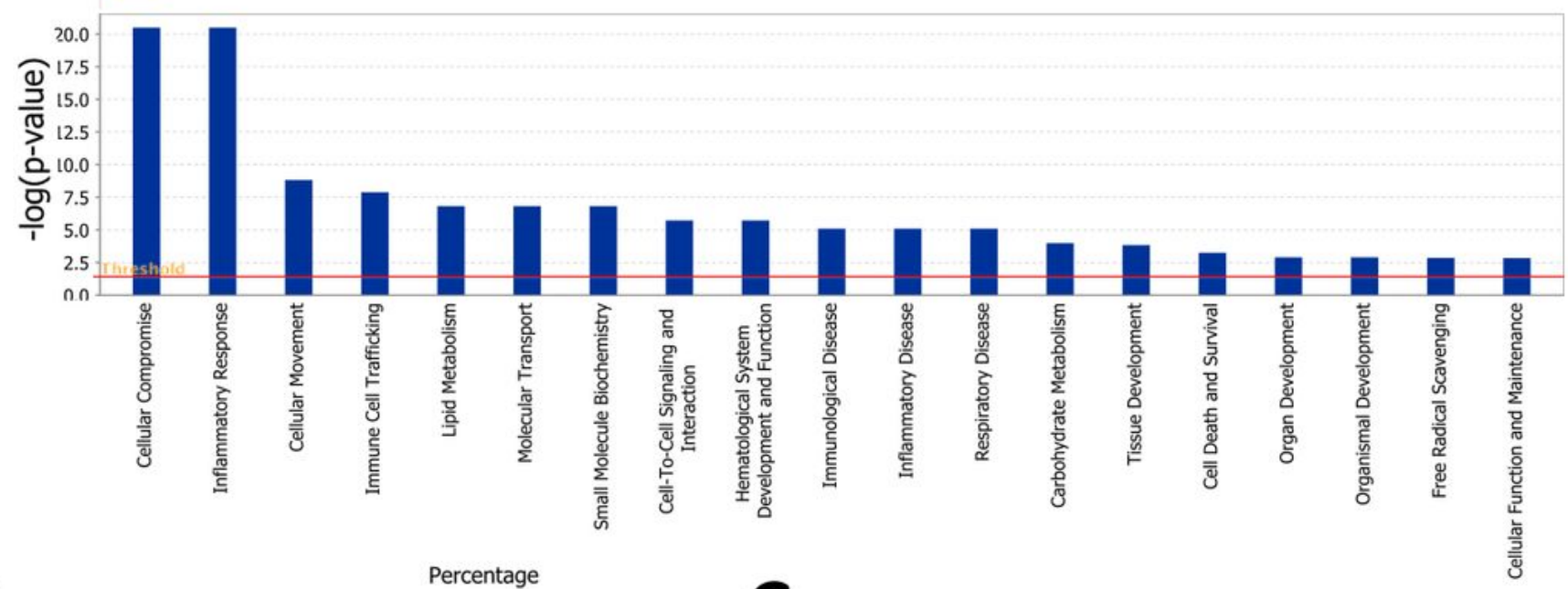

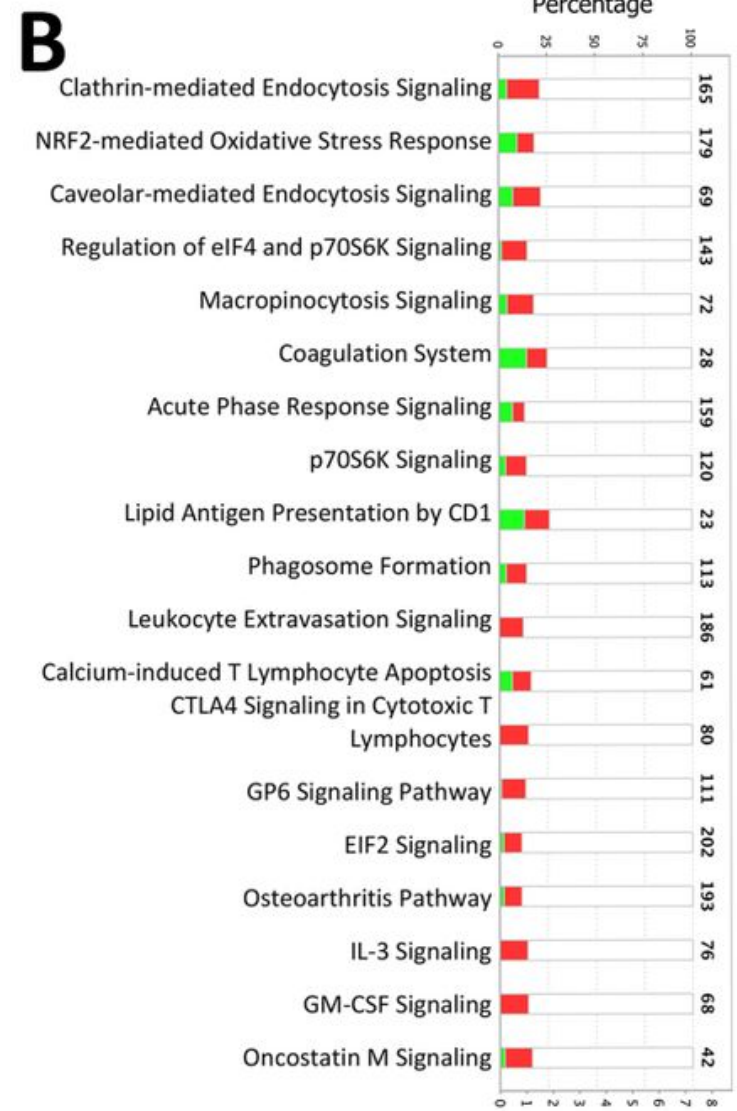

-log(p-value)

Downregulated $\mathbf{1}$ No change Upregulated $\square$ No overlap with dataset

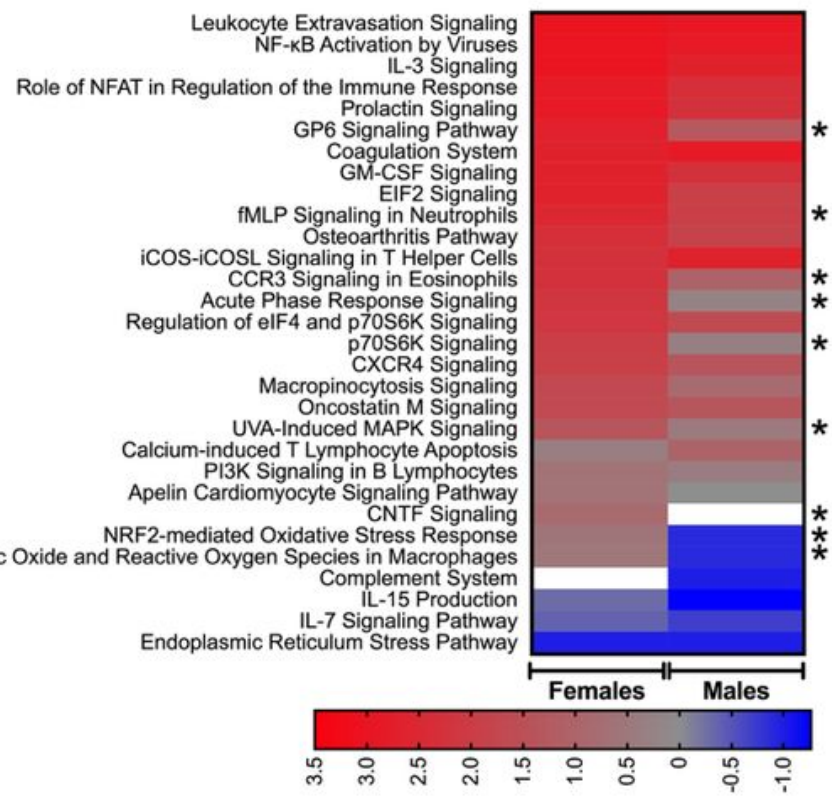

Figure 7

Figure 7

Comparative analysis of proteins in BALF exosomes from ozone- vs air-exposed mice reveals enrichment of inflammation/injury associated pathways. 1255 differentially enriched proteins (Total,1255; enriched, 
568; low-abundance, 687) were subjected to Ingenuity pathway analysis (IPA). Ingenuity pathway analysis (IPA) for the enrichment of (A) disease/functional pathways and (B) canonical pathways/biological networks altered in the exosomes from ozone-exposed mice. (C) IPA was performed compare differentially expressed signatures in ozone-exposed males (versus air-exposed males; 380 , enriched; 438, low abundance) and ozone-exposed females (versus air-exposed females; 427, enriched; 474 , low abundance). Z-scores were used to plot heat maps. Only selected pathways are presented in this figure. A detailed heat map with all the differentially enriched pathways is included in Supplemental Fig. 2.

\section{Supplementary Files}

This is a list of supplementary files associated with this preprint. Click to download.

- SuppTables14Proteomics.xlsx

- SupplemetalFigures13proteomicswithFirstpage.pdf 